\title{
Article \\ Acute Inflammation Induces Neuroendocrine and Opioid Receptor Genes Responses in the Seabass Dicentrarchus labrax Brain
}

\author{
Rita Azeredo ${ }^{1, *(\mathbb{D})}$, Marina Machado ${ }^{1}\left(\mathbb{D}\right.$, Patricia Pereiro ${ }^{1,2}(\mathbb{D})$, Andre Barany ${ }^{3}\left(\mathbb{D}\right.$, Juan Miguel Mancera ${ }^{3}(\mathbb{D})$ \\ and Benjamín Costas $1,4, *$ (D)
}

1 Centro Interdisciplinar de Investigação Marinha e Ambiental (CIIMAR), Universidade do Porto, 4450-208 Matosinhos, Portugal; mcasimiro@ciimar.up.pt (M.M.); patriciapereiro@iim.csic.es (P.P.)

2 Instituto de Investigaciones Marinas (IIM-CSIC), 36208 Vigo, Spain

3 Department of Biology, Faculty of Marine and Environmental Sciences, Instituto Universitario de Investigación Marina (INMAR), Campus de Excelencia Internacional del Mar (CEI·MAR), University of Cadiz, 11519 Puerto Real, Spain; andre.barany@uca.es (A.B.); juanmiguel.mancera@uca.es (J.M.M.)

4 Instituto de Ciências Biomédicas Abel Salazar (ICBAS-UP), Universidade do Porto, 4050-313 Porto, Portugal

* Correspondence: mleme@ciimar.up.pt (R.A.); bcostas@ciimar.up.pt (B.C.)

check for updates

Citation: Azeredo, R.; Machado, M.; Pereiro, P.; Barany, A.; Mancera, J.M.; Costas, B. Acute Inflammation Induces Neuroendocrine and Opioid Receptor Genes Responses in the Seabass Dicentrarchus labrax Brain. Biology 2022, 11, 364. https:// doi.org/10.3390/biology11030364

Academic Editors: Geert F. Wiegertjes and Brian Dixon

Received: 19 January 2022

Accepted: 21 February 2022

Published: 24 February 2022

Publisher's Note: MDPI stays neutral with regard to jurisdictional claims in published maps and institutional affiliations.

Copyright: (C) 2022 by the authors. Licensee MDPI, Basel, Switzerland. This article is an open access article distributed under the terms and conditions of the Creative Commons Attribution (CC BY) license (https:// creativecommons.org/licenses/by/ $4.0 /)$.
Simple Summary: It is generally accepted (in mammals and in teleost fish, too) that stressful conditions affect the performance of an immune response. What is still far from being known is at what extend does an immune process affects the neuroendocrine system. Vaccination for instance, is nowadays a common practice in aquaculture and little is known about its physiological implications other than immunization. Here is a first approach to the study of the European seabass' brain gene expression patterns in response to a peripheral inflammatory process. Genes related to the stress response were focused, along with those related to the opioid system. Increased expression of certain genes suggests the activation of a stress response triggered by inflammatory signals. Additionally, contrasting expression patterns of the same gene (increased vs decreased) in the different brain regions (as well as the time needed for changes to happen) point at different functions. These results clearly show the reactivity of different brain responses to an immune response, highlighting the importance of further studies on downstream implications (behavior, feeding, welfare, reproduction).

\begin{abstract}
In fish, as observed in mammals, any stressful event affects the immune system to a larger or shorter extent. The neuroendocrine-immune axis is a bi-directional network of mobile compounds and their receptors that are shared between both systems (neuroendocrine and immune) and that regulate their respective responses. However, how and to what extent immunity modulates the neuroendocrine system is not yet fully elucidated. This study was carried out to understand better central gene expression response patterns in a high-valued farmed fish species to an acute peripheral inflammation, focusing on genes related to the hypothalamus-pituitary-interrenal axis and the opioid system. European seabass, Dicentrarchus labrax, were intra-peritoneally injected with either Freund's Incomplete Adjuvant to induce a local inflammatory response or Hanks Balances Salt Solution to serve as the control. An undisturbed group was also included to take into account the effects due to handling procedures. To evaluate the outcomes of an acute immune response, fish were sampled at $4,24,48$, and $72 \mathrm{~h}$ post-injection. The brain was sampled and dissected for isolation of different regions: telencephalon, optic tectum, hypothalamus, and pituitary gland. The expression of several genes related to the neuroendocrine response was measured by real-time PCR. Data were statistically analyzed by ANOVA and discriminant analyses to obtain these genes' responsiveness for the different brain regions. Serotonergic receptors were upregulated in the telencephalon, whereas the optic tectum inhibited these transcription genes. The hypothalamus showed a somewhat delayed response in which serotonin and glucocorticoid receptors were concerned. Still, the hypothalamic corticotropinreleasing hormone played an important role in differentiating fish undergoing an inflammatory response from those not under such conditions. Opioid receptors gene expression increased in
\end{abstract}


both the hypothalamus and the telencephalon, while in the optic tectum, most were downregulated. However, no changes in the pituitary gland were observed. The different brain regions under immune stimulation demonstrated clear, distinct responses regarding gene transcription rates as well as the time period needed for the effect to occur. Further, more integrative studies are required to associate functions to the evaluated genes more safely and better understand the triggering mechanisms.

Keywords: genomics; stress response; HPI-axis; neuroendocrine-immune interaction

\section{Introduction}

Inadequate aquaculture rearing conditions (husbandry, transportation, crowding densities, water parameters, etc.) often result in stressful environments that compromise fish growth and welfare [1-3]. Although these are the most obvious and relevant outcomes for fish farmers, other physiological responses, such as fish immune defenses, can be similarly compromised. Indeed, the extension of stress effects on fish health has mainly been investigated. It is now generally acknowledged that chronic stressful rearing conditions jeopardize fish immune response since it downregulates several immune defense mechanisms [4]. A fish farm ultimately decreases fish immune resistance upon a disease outbreak, leading to high mortalities.

Neuroendocrine and immune responses are tightly connected in what is known as the neuroendocrine-immune axis that comprises both the brain and the head-kidney. Teleost fish head-kidney presents endocrine and immune tissues as well as a complex paracrine signaling network, acting as an intermediary organ between neuroendocrine and immune systems. Neuroendocrine-immune processes are bidirectional, and so not only does stress (internal or external) modulate the immune response, but immunological processes are also able to trigger the hypothalamus-pituitary-interrenal (HPI) axis [5].

The regulators and effectors of these modulatory mechanisms belong to several molecular classes-from neuropeptides, opioids, and neurotransmitters to interleukins and chemokines. Moreover, several of these players are shared by both systems (immune and neuroendocrine). A fair amount of studies has been devoted to evaluating stress-induced effects on fish immunity. Most of these studies used cortisol as the primary stress marker as well as plasma glucose and lactate as indicators of secondary stress responses [6]. Upstream, hypothalamic corticotropin-releasing hormone $(\mathrm{crh})$ and corticotropin-releasing hormone binding protein ( $c r h b p)$, as well as pituitary proopiomelanocortin (pomc) gene expression are also good primary stress markers [7]. Serotonin, a tryptophan metabolite that mostly acts as a neurotransmitter at central levels, also presents a role in the stress responses modulating corticotropin-releasing hormone (CRF) and adrenocorticotropin hormone (ACTH) secretion. Often, when stress-inducing factors are persistent, this neuroendocrine response becomes chronic and suppresses immune mediators' function, both by a metabolic reorganization that reduced influx of energy and by a direct inhibitory effect of cortisol $[4,8,9]$.

Although the bidirectional aspect of this neuroendocrine-immune axis is wellacknowledged, the effects that an immunological process have on the HPI axis are far more disregarded than those inflicted by stress on immunity. In fish, such mechanisms have been reviewed by Verburg-van Kemenade and co-workers [5] and in more detail by Engelsma and colleagues [10], where the role of cytokines is given particular emphasis, as well as the pathways through which an immune process communicates with the central nervous system. Nonetheless, the neuronal arm of the HPI axis has far more branches connecting to the central backbone of the $\mathrm{CRH}$ and $\mathrm{ACTH}$ [7]. In this way, the serotonergic system, for instance, not only operates mood and behaviour but it also regulates the stress response (and ultimately cortisol release) using a considerable network of serotonin receptors [11-13]. Specifically, these receptors present a widespread brain distribution; however, it is not homogenous throughout different brain regions both in terms of abundancy and of identity, suggesting distinct functions and reactivity [14]. 
Likewise, and though comparatively even less explored, opioid receptors display a ubiquitous central distribution that is linked to their diverse plethora of functions. Opioids have long been associated to mood, behaviour, and nociception in fish [15]. However, they are also involved in regulatory mechanisms of both the immune and the stress responses [16,17]. At least in what carp (Cyprinus carpio) is concerned, opioids effects in leucocytes have been shown to be evolutionarily conserved [18]. Nevertheless, their exact roles and responsiveness to immune stimulation in the brain are still not known.

In an attempt to further understand the extent of peripheral immune signaling impact on central neuroendocrine responses, the present study intends to unveil and characterize the central neuronal gene expression profile, focusing on neuroendocrine and opioid receptors, in response to an acute peripheral inflammation in a marine fish species, the European seabass (Dicentrarchus labrax).

\section{Material and Methods}

\subsection{Fish and Experimental Design}

European seabass juveniles ( $n=72,87.3 \mathrm{~g} \pm 16.5$ body mass) were acquired from a certificated hatchery (MARESA, Spain) and maintained at the facilities of Servicios Centrales de Investigación en Cultivos Marinos (SCI-CM, CASEM, University of Cadiz, Puerto Real, Cádiz, Spain; Facilities for Breeding, Supplying and Users of Experimental Animals; Spanish Operational Code REGA ES11028000312). The fish were acclimated for 2 weeks in a flow-through $2 \mathrm{~m}^{3}$-tank. They were then transferred to a flow-through seawater system composed of sixteen 80 L-fiber glass tanks and fed a commercial diet for 30 days. The fish were maintained under natural photoperiod (June-July 2017, 36 $31^{\prime} 45^{\prime \prime} \mathrm{N}$, $\left.6^{\circ} 11^{\prime} 31^{\prime \prime} \mathrm{W}\right)$, temperature $\left(18-19^{\circ} \mathrm{C}\right)$, and salinity $\left(39 \mathrm{~g} \mathrm{~L}^{-1}\right)$. Supplemental aeration was provided to maintain dissolved oxygen at $6.8 \pm 0.4 \mathrm{mg} \mathrm{L}^{-1}$. Ammonia $\left(<0.1 \mathrm{mg} \mathrm{L}^{-1}\right)$, nitrite $\left(<0.2 \mathrm{mg} \mathrm{L}^{-1}\right)$, and nitrate $\left(<50 \mathrm{mg} \mathrm{L}^{-1}\right)$ were determined once weekly. Fish were fed twice per day (9:00 a.m. and 1:00 p.m.) at a rate of $2 \%$ of their body weight over the 30-day feeding trial. At the end of this period, eight fish were netted and euthanized by anaesthetic overdose ( $1 \mathrm{~mL}$ of 2-phenoxyethanol $1^{-1}$ seawater; Merck, Darmstadt, Germany). Brains were collected and dissected into telencephalon, optic tectum, hypothalamus, and pituitary gland. Samples were kept in RNAlater (Sigma) at $4{ }^{\circ} \mathrm{C}$ for $24 \mathrm{~h}$ and finally stored at $-20{ }^{\circ} \mathrm{C}$ until further processing. This group of fish, sampled before any intervention, was subsequently designated as undisturbed fish $(0 \mathrm{~h})$. The remaining fish were anesthetized $(0.5 \mathrm{~mL}$ of 2-phenoxyethanol $1^{-1}$ seawater) and intraperitoneally (i.p.) injected with $100 \mu \mathrm{L}$ of either Freund's Incomplete Adjuvant (FIA) to induce inflammation [19], or Hanks Balanced Salt Solution (HBSS) to serve as a sham group (CTRL), and reallocated in duplicate tanks of the original system for each experimental condition ( $n=8$ per condition). The fish were then sampled at $4,24,48$, and $72 \mathrm{~h}$, as previously described, following i.p. injection ( $\mathrm{n}=4$ per tank, $\mathrm{n}=8$ per time and experimental group). They were fasted for $24 \mathrm{~h}$ before sampling and i.p. injection as well as during the experimental time.

All the experimental procedures complied with the University of Cádiz (Spain) guidelines and the European Union Council (2010/63/EU) to use animals in research. The experimental procedures were previously approved by the Spanish Government's Ethics and Animal Welfare Committee (RD53/2013) and endorsed by the Regional Government (Junta de Andalucía reference number 28-04-15-241). All animal protocols were performed under Group-D licenses accredited by FELASA (Federation of European Laboratory Animal Science Associations).

\subsection{Gene Expression}

Total RNA isolation was conducted with the NZY Total RNA Isolation kit (NZYTech, Lisbon, Portugal) following the manufacturer's specifications. RNA was quantified using the DS-11 Spectrophotometer (DeNovix), and first-strand cDNA was synthesized with NZY First-Strand cDNA Synthesis Kit (NZYTech, Lisbon, Portugal). Quantitative PCR assays were performed with CFX384 Touch Real-Time PCR Detection System, using $4.4 \mu \mathrm{L}$ 
of diluted cDNA mixed with $5 \mu \mathrm{L}$ of NZYSpeedy qPCR Green Master Mix ${ }^{\circledR}$ and $0.3 \mu \mathrm{L}$ $(10 \mu \mathrm{M})$ of each specific primer in a final volume of $10 \mu \mathrm{L}$. The cDNA amplification was carried out with specific primers for genes that have been selected for their involvement in the neuroendocrine response. Primers were designed with NCBI Primer Blast Tool and IDT OligoAnalyzer Tool ${ }^{\mathrm{TM}}$, respecting known qPCR restrictions (amplicon size, Tm difference between primers, GC content, and self-dimer or crossdimer formation). Part of the template sequences were obtained from available data in NCBI, while others were identified after searching the databases dicLab v1.0c seabass genome [20] and designed as previously described. The efficiency of primer pairs was analysed in serial, 2-fold dilutions of cDNA by calculating the slope of the regression line of the cycle thresholds $(\mathrm{Ct})$ vs. the relative concentration of cDNA. Accession number, efficiency values, annealing temperature, product length, and primers sequences are presented in Table 1. Melting curve analysis was also performed to verify that no primer dimers were amplified. The standard cycling conditions were $95^{\circ} \mathrm{C}$ initial denaturation for $10 \mathrm{~min}$, followed by 40 cycles of two steps $\left(95^{\circ} \mathrm{C}\right.$ denaturation for $15 \mathrm{~s}$ followed by primer annealing temperature for $1 \mathrm{~min}$ ), $95^{\circ} \mathrm{C}$ for $1 \mathrm{~min}$ followed by $35 \mathrm{~s}$ at the annealing temperature, and finally, $95^{\circ} \mathrm{C}$ for $15 \mathrm{~s}$. All reactions were carried out as technical duplicates. The expression of the target genes was normalized using the geometric mean of European seabass ribosome 40s subunit (40s) and elongation factor $1 \alpha(e f 1 \alpha)$ expression levels and calculated according to the Pfaffl method [21].

\subsection{Statistical Analysis}

Gene expression values are presented as mean \pm standard deviation (mean $\pm \mathrm{SD}$ ). Data were analysed for normality and homogeneity of variance, and, when necessary, outliers were removed, and data were log-transformed before being treated statistically. Possible i.p. injection effects were detected by One-way ANOVA, while inflammation- and sampling time-induced effects were identified using a two-way ANOVA. When statistical significance was detected, ANOVA analyses were followed by Tukey post-hoc test to identify differences within experimental treatments. These statistical analyses were performed using the computer package Statistica 13 for Windows. The level of significance used was $p \leq 0.05$ for all statistical tests. In an attempt to discriminate and characterize brain regions of fish under inflammatory conditions, a multivariate canonical discriminant analysis was performed on each brain region dataset. Thereby, numerous combinations of the original variables (discriminant functions) were evaluated. Each discriminant function explains part of the total variance of the dataset and is loaded by variables contributing the most to that variation. Wilk's $\lambda$ test assessed discriminatory effectiveness, and the distance between group centroids was measured by squared Mahalanobis distance. To attest whether these distances were statistically significant, Fisher's F statistic was performed. Discriminant analyses were carried out using the data analysis tool XLSTAT for Microsoft Office Excel, and a significance level of $95 \%(p \leq 0.05)$ was used. 
Table 1. Forward and reverse primers for real-time PCR.

\begin{tabular}{|c|c|c|c|c|c|c|}
\hline Acronym & GenBank & Eff $^{2}$ & $\mathrm{AT}^{3}$ & Product Length $^{4}$ & Forward Primer Sequence & Reverse Primer Sequence \\
\hline $40 s$ & HE978789.1 & 108.8 & 60 & 79 & TGATTGTGACAGACCCTCGTG & CACAGAGCAATGGTGGGGAT \\
\hline ef $1 \alpha$ & AJ866727.1 & 92.8 & 57 & 144 & AACTTCAACGCCCAGGTCAT & CTTCTTGCCAGAACGACGGT \\
\hline$g r 1$ & AY619996.1 & 114.19 & 60 & 100 & AAATCTGCCTGGTGTGTTCC & TGCССТTTCACTGCTCTCTT \\
\hline crh & JF274994.1 & 110.21 & 60 & 200 & AАСССАAАACTCCCAGCAG & TGTTCCCAACTTTCССТTGT \\
\hline$c r h b p$ & MG832822.1 & 105.47 & 60 & 199 & TGTCATCTCCCAGTCACCAG & GCCATTTCCTCCAAGCAAC \\
\hline pomc & AY691808.1 & 101.98 & 60 & 158 & ТСТТССТССТССТСТССАСА & CGCСТTCTCATCTCTTCAGG \\
\hline htr1aß & DLAgn_00119560 ${ }^{1}$ & 102.0 & 60 & 176 & GGAGCGTAAAACGGTGAAAA & TGGGGTTGAGGAGAGAGTTG \\
\hline$h t r 2 b$ & DLAgn_00148380 ${ }^{1}$ & 109.4 & 60 & 165 & ATTGCCCTCGTCACTGTTCT & GCTGTGTTGGATTGGCTTCT \\
\hline$h t r 2 c$ & DLAgn_00037670 1 & 118.0 & 60 & 195 & CATCCGCAACCCCATAGAG & ACGAAGGAGCCAATCAGCAT \\
\hline tph1 & DLAgn_00154580 ${ }^{1}$ & 107.0 & 62 & 114 & CGCATAGACTTCACAACAGAGG & CAGCAGAGGGAGGTTCTTCA \\
\hline$o g f r 1$ & DLAgn_00128530 ${ }^{1}$ & 96.8 & 60 & 185 & GTTGGGAATGGAGATGGAAA & GCTTCAGATTTTGGCTCAGG \\
\hline$o g f r 2$ & DLAgn_00089660 ${ }^{1}$ & 96.6 & 60 & 146 & CTTGCCTTCCTGTCTCCAGT & CTTGTCTCGGTTTCCTTTGG \\
\hline kor1 & DLAgn_00007470 1 & 89.7 & 60 & 249 & TCTGGTGCTTGTGGTAGTCG & TGGCAGTCTCTGTGTCCTTG \\
\hline kor2 & DLAgn_00077520 ${ }^{1}$ & 82.0 & 60 & 163 & CTCGTCAGTGTCCCCGAAAC & CССССTTCAGTTTGGCCGAGAG \\
\hline nopr & DLAgn_00125610 ${ }^{1}$ & 97.5 & 60 & 106 & СТССТTTCTCATCCCTGTGG & GTTGCGGTCCTTTTCCTTG \\
\hline muor & DLAgn_00015310 ${ }^{1}$ & 99.8 & 60 & 240 & GTCACCAGCACCCTACCATT & CGAGGAGAGAATCCAGTTGC \\
\hline
\end{tabular}

${ }^{3}$ Annealing temperature $\left({ }^{\circ} \mathrm{C}\right) .{ }^{4}$ Amplicon (nt). 


\section{Results}

For clarity, the results are presented in two main subsections: (i) the first one gathers genes more directly related to the HPI-axis response (results from Section 3.1), and (ii) the second one looks separately at the opioid receptors response. Notwithstanding their involvement in the same neuroendocrine pathways, they are relatively poorly studied for their role during inflammation (results from Section 3.2). Moreover, within each subsection and given the amount of data collected, relevance will be granted to (i) the i.p. injection effect and (ii) inflammation-induced changes. Intraperitoneal injection per se (regardless of content nature) was considered to modulate neuroendocrine gene expression patterns when both groups simultaneously behaved significantly differently from undisturbed fish $(0 \mathrm{~h})$. Inflammation was thought to affect gene expression whenever (i) there were significant differences between CTRL and FIA groups or (ii) whenever there was a difference between $0 \mathrm{~h}$ and FIA fish, without CTRL being different from $0 \mathrm{~h}$. Due the high amount of results obtained, the complete set of gene expression results is provided as a Supplementary File.

\subsection{HPI-Axis Response}

\subsubsection{Telencephalon}

Serotonin receptor 2A ( $h$ tr $2 b$ ) expression was upregulated in FIA-injected group, regardless of sampling point (Supplementary File, Table S1). Telencephalic expression of $h t r 2 b$ and serotonin receptor $2 \mathrm{C}(h t r 2 c)$ was higher in FIA-injected fish at $4 \mathrm{~h}$ than in $0 \mathrm{~h}$ group (Figure 1A,B respectively). FIA-injected fish enhanced serotonin receptor $1 \mathrm{~A} \beta$ ( $h$ tr1a $\beta$ ) expression levels with respect to CTRL at $48 \mathrm{~h}$ (Supplementary File, Table S1). Glucocorticoid receptor 2 ( $g r 2)$ was downregulated at $72 \mathrm{~h}$ in both injected groups (Supplementary File, Table S1). No significant differences between FIA, CTRL, and $0 \mathrm{~h}$ groups were observed regarding glucocorticoid receptor 1 ( $g r 1)$ and tryptophan hydroxylase 1 (tph1) gene expression, although both genes were downregulated over time, irrespective of treatment.

\section{A}
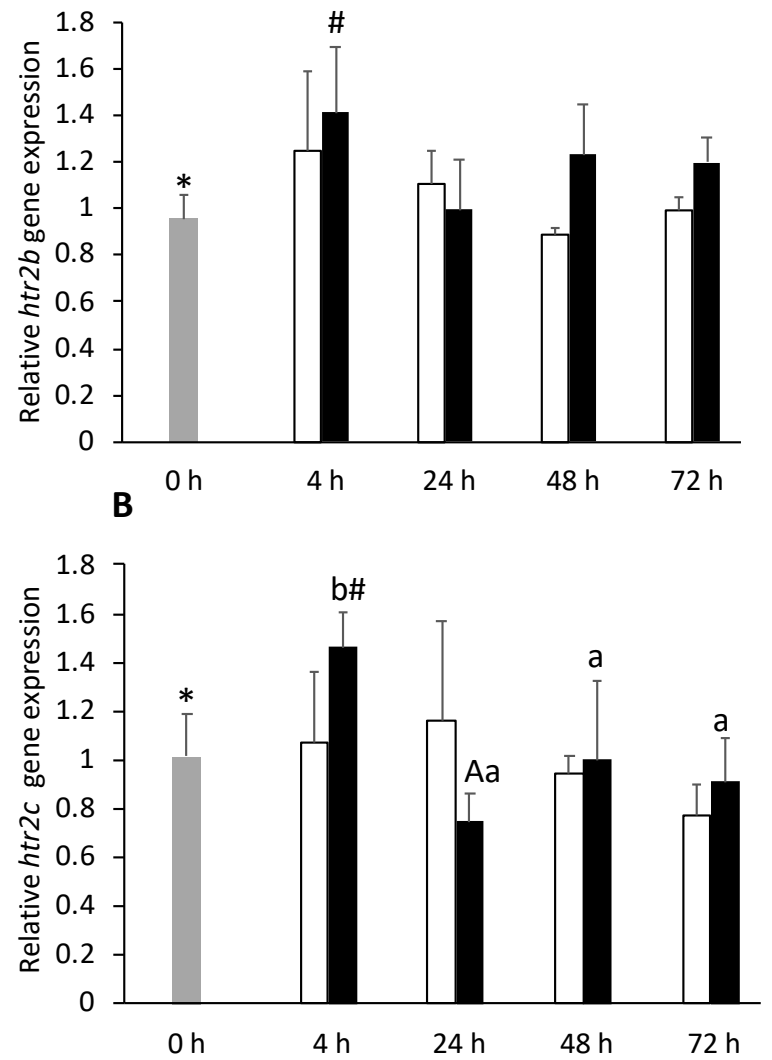

Figure 1. Telencephalic expression of serotonin receptors $2 \mathrm{~B}(h t r 2 b, \mathbf{A})$ and $2 \mathrm{C}(h t r 2 c, \mathbf{B})$ in undisturbed 
European seabass $(0 \mathrm{~h}, \square)$ or i.p.-injected with a sham solution (CTRL, $\square$ ) or Freund's Incomplete Adjuvant (FIA, $\mathbf{-}$ ) and sampled at 4, 24, 48, $72 \mathrm{~h}$ post-injection (means $\pm \mathrm{SD}, \mathrm{n}=8$ ). One-way ANOVA was performed to identify differences between i.p.-injected fish and the undisturbed group, followed by a Tukey post-hoc test. Different symbols $\left({ }^{*}, \#\right)$ stand for significant differences between i.p.-injected groups and the undisturbed group $(0 \mathrm{~h})$. Two-way ANOVA was performed to identify significant differences within the i.p.-injected fish, followed by a Tukey post-hoc test. Capital letters stand for significant differences between stimuli. Lower-case letters indicate significant differences between sampling times $(p \leq 0.05)$.

When evaluating linear functions of HPI-related variables in the telencephalon and their contributions to differences between $0 \mathrm{~h}$ and FIA groups (FIA4, FIA24, FIA48, FIA72), the overall discriminant analysis performance was very reasonable (Wilks $\lambda=0.19, p=0.04$ ). It resulted in four discriminant functions, with the first two accounting for $79.2 \%$ of the total variability (Figure 2A). The first discriminant function (F1, 44\%) was negatively loaded by $g r 1, g r 2, h t r 2 a$, and $h t r 2 c$ (i.e., lower gene expression) (Figure 2A, correlations of -0.62 , $-0.64,-0.62,-0.78$, respectively) whereas the second function (F2, 35.25\%) was positively loaded by $h t r 2 b$ (i.e., higher gene expression) (Figure $2 \mathrm{~A}$, correlation of 0.86 ). The analysis of Mahalanobis distances between groups' multivariate means demonstrated that FIA4, FIA48, and FIA72 differed from $0 \mathrm{~h}$, and that FIA4 differed from FIA24 and FIA72 $(p<0.05$, Figure 2B).

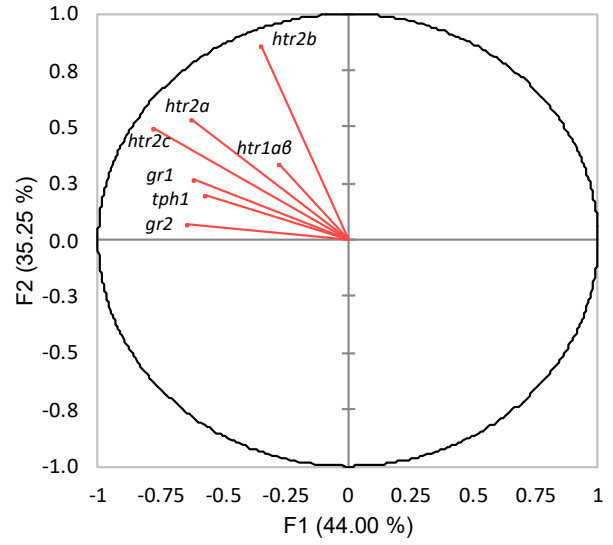

(A)

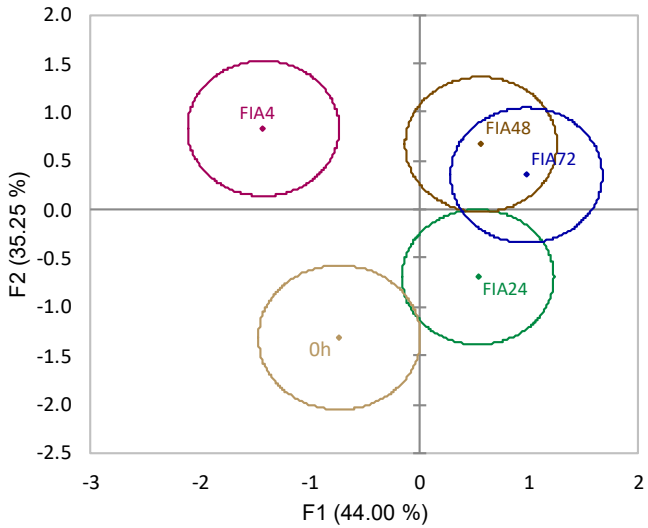

(B)

Figure 2. Canonical discriminant analysis of European seabass telencephalic expression of HPI-axisrelated genes. (A) Correlation variables/factors (factor loads) for two main discriminant functions (F1 and F2); gr1, glucocorticoid receptor $1 ;$ gr2, glucocorticoid 2; htr1a $\beta$, serotonin receptor $1 \mathrm{~A} \beta ;$ tr $2 a$, serotonin receptor $2 \mathrm{~A} ; h t r 2 b$, serotonin receptor $2 \mathrm{~B} ; h t r 2 c$, serotonin receptor $2 \mathrm{C}$; $t p h 1$, tryptophan hydroxylase 1. (B) Canonical discriminant scores of each group. Group centroids are marked by a small diamond, whereas circles indicate data distribution per group.

\subsubsection{Optic Tectum}

An extended gene expression suppression was observed in the FIA group compared to the CTRL group, regardless of the sampling point. Similar to $h t r 2 c$ (Figure 3A), gr1, $h t r 1 a \beta$, and $h$ tr $2 a$ were all downregulated (Supplementary File, Table S2). In the same way, $g r 2$ gene expression decreased in FIA-injected fish at $4 \mathrm{~h}$ compared to both $0 \mathrm{~h}$ and CTRL groups (Figure 3B). No significant differences were observed regarding both $h t r 2 b$ and $t p h 1$. 
A
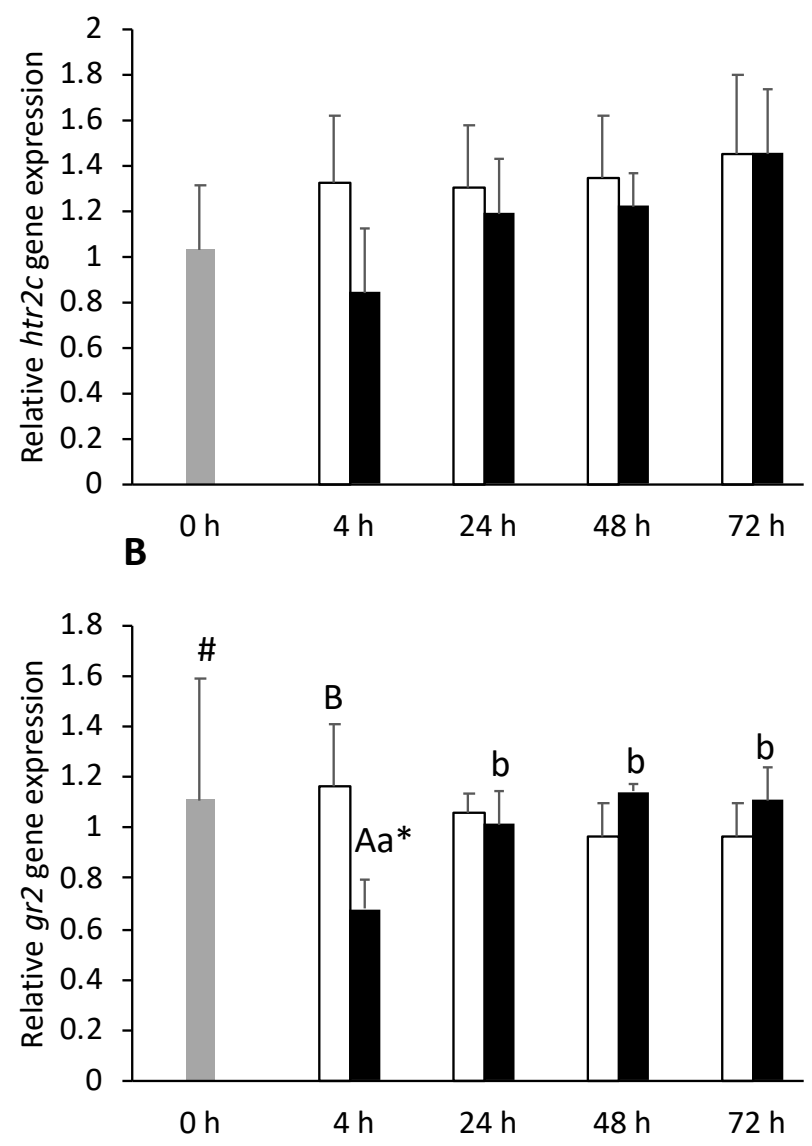

Figure 3. Optic tectum expression of serotonin receptor $2 \mathrm{C}(h t r 2 c, \mathbf{A})$ and glucocorticoid receptor 2 $(g r 2$, B $)$ in undisturbed European seabass $(0 \mathrm{~h}, \square)$ or i.p.-injected with a sham solution (CTRL, $\square)$ or Freund's Incomplete Adjuvant (FIA, - ) and sampled at 4, 24, 48, $72 \mathrm{~h}$ post-injection (means \pm SD, $\mathrm{n}=8$ ). Different symbols ( ${ }^{*}$ and \#) stand for significant differences between i.p.-injected groups and the undisturbed group $(0 \mathrm{~h})$. Capital letters stand for significant differences between stimuli. Lower-case letters indicate significant differences between sampling times. Further details in legend of Figure 1.

The discriminant analysis to neuroendocrine-related genes was also statistically significant (Wilks $\lambda=0.27, p=0.04$ ), with the first two discriminant functions explaining $93.3 \%$ of the data total variability (Figure 4$)$. The first discriminant function $(\mathrm{F} 1,85.5 \%)$ was positively loaded by both $g r 2$ and $h t r 2 c$ (i.e., higher expression) (Figure $4 \mathrm{~A}$, correlations of 0.62 and 0.68 , respectively), whereas the second function (F2, 7.8\%) was positively loaded by gr1 (i.e., higher expression) (Figure $4 \mathrm{~A}$, correlation of 0.70 ). The analysis of Mahalanobis distances between groups' multivariate means demonstrated that FIA4 was significantly different from FIA24, FIA48, and FIA72 ( $p<0.05$, Figure 4B).

\subsubsection{Hypothalamus}

Gene expression of $g r 1$ was upregulated by i.p. injection, being higher at $48 \mathrm{~h}$ in the FIA group, compared to the CTRL group (Figure 5A). A similar feature was observed for gr2 expression (data not shown). In addition, corticotropin-releasing hormone ( $c r h$ ) expression was upregulated by i.p. injection whereas tph 1 transcription significantly decreased (Supplementary File, Table S3). Expression levels of $h t r 1 a \beta$ were higher at $48 \mathrm{~h}$ in the FIA group compared to the CTRL group (Figure $5 B$ ). No significant differences between the FIA and CTRL groups were detected regarding corticotropin-releasing hormone-binding protein (crhbp) and tph1 gene expression (Supplementary File, Table S3). 


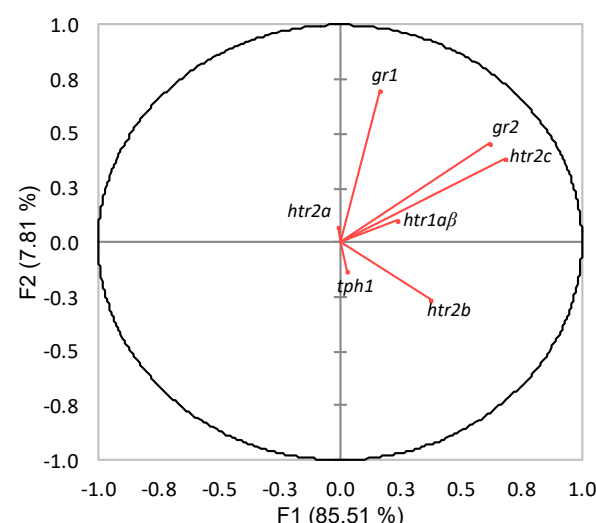

(A)

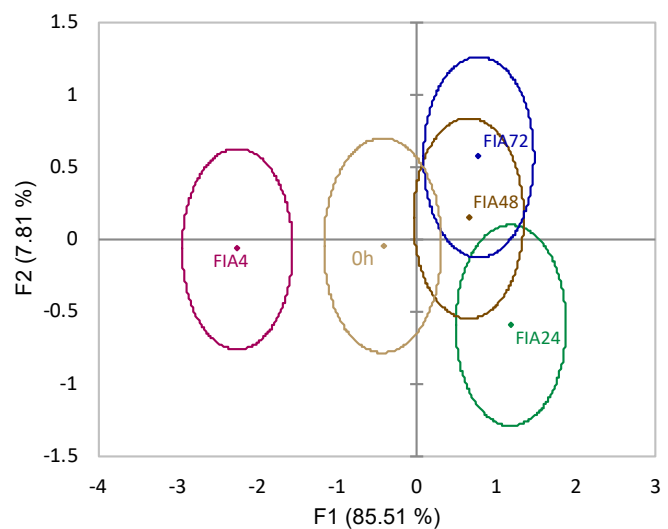

(B)

Figure 4. Canonical discriminant analysis of European seabass optic tectum expression of HPI-axisrelated genes. (A) Correlation variables/factors (factor loads) for two main discriminant functions (F1 and F2); gr1, glucocorticoid receptor $1 ;$ gr2, glucocorticoid 2 ; htr1a $\beta$, serotonin receptor $1 \mathrm{~A} \beta ;$ tr $2 a$, serotonin receptor $2 \mathrm{~A}$; $h t r 2 b$, serotonin receptor $2 \mathrm{~B} ; h t r 2 c$, serotonin receptor $2 \mathrm{C}$; $t p h 1$, tryptophan hydroxylase 1. (B) Canonical discriminant scores of each group. Group centroids are marked by a small diamond, whereas circles indicate data distribution per group.

A

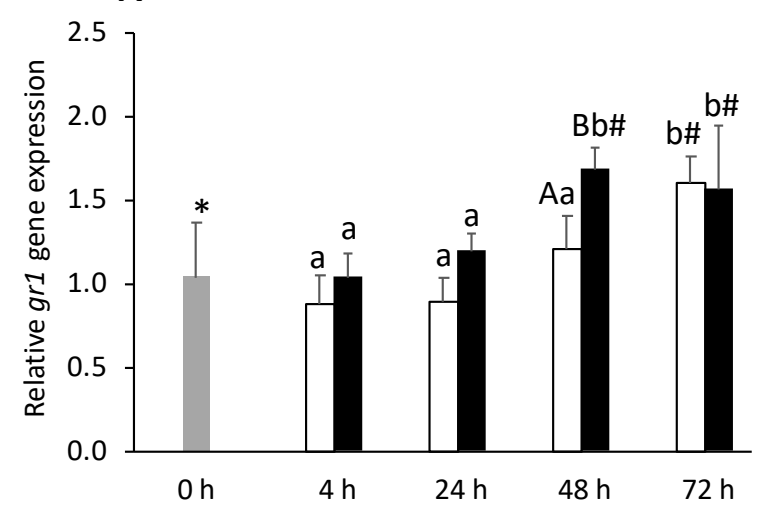

B

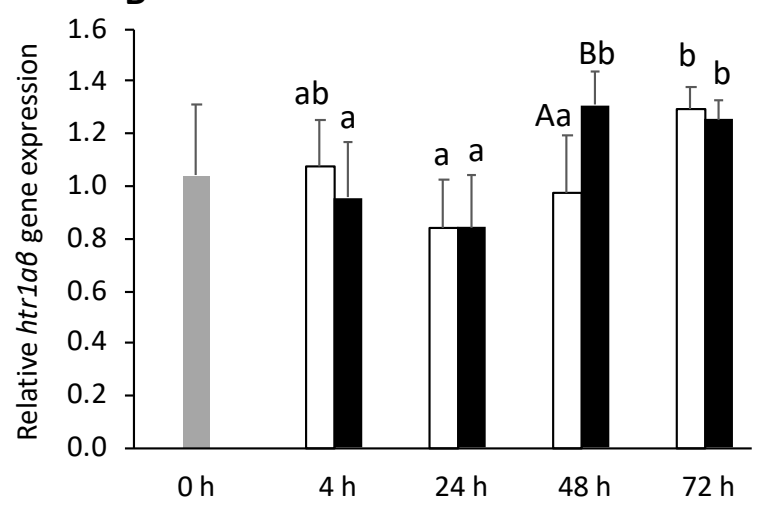

Figure 5. Hypothalamic expression of glucocorticoid receptor $1(\mathrm{gr} 1, \mathbf{A})$ and serotonin receptor $1 \mathrm{~A} \beta$ $(h t r 1 a \beta, \mathbf{B})$ in undisturbed European seabass $(0 \mathrm{~h}, \square)$ or i.p.-injected with a sham solution $(\mathrm{CTRL}, \square)$ or Freund's Incomplete Adjuvant (FIA, $\mathbf{m}$ ) and sampled at 4, 24, 48, $72 \mathrm{~h}$ post-injection (means \pm SD, $\mathrm{n}=8$ ). Different symbols ( ${ }^{*}$ and \#) stand for significant differences between i.p.-injected groups and the undisturbed group $(0 \mathrm{~h})$. Capital letters stand for significant differences between stimuli. Lower-case letters indicate significant differences between sampling times. Further details in legend of Figure 1. 
Neuroendocrine variables discriminant analysis (Wilks $\lambda=0.12, p=0.002$ ) produced four discriminant functions from which the first two accounted for $77.4 \%$ of the total dataset variability (Figure 6). The first function (F1, 53.6\%) was positively loaded by gr1, gr2, crh, crhbp, and $h t r 1 a \beta$ (i.e., higher expression) (Figure 6A, correlations of 0.70, 0.68, 0.66, 0.69, and 0.60 , respectively) while no significant loadings were attributed to the second function (F2, 23.8\%).The analysis of Mahalanobis distances between groups' multivariate means demonstrated that the t0h group was significantly different from FIA24 and FIA72, FIA4 was different from FIA72, and FIA24 differed from FIA48 and FIA72 $(p<0.05$, Figure 6B).

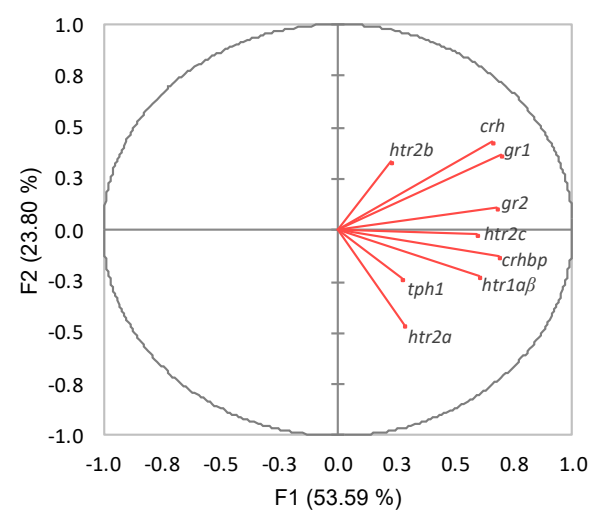

(A)

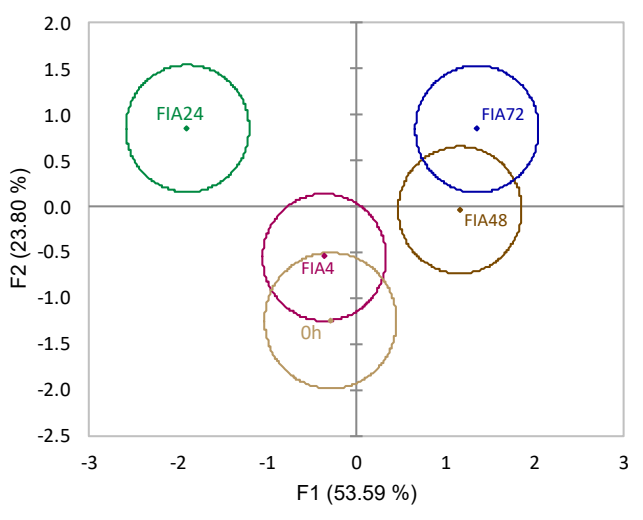

(B)

Figure 6. Canonical discriminant analysis of European seabass hypothalamic expression of HPI-axisrelated genes. (A) Correlation variables/factors (factor loads) for two main discriminant functions (F1 and F2); gr1, glucocorticoid receptor 1; gr2, glucocorticoid 2; htr1a $\beta$, serotonin receptor $1 \mathrm{~A} \beta ;$ tr $2 a$, serotonin receptor $2 \mathrm{~A} ; h t r 2 b$, serotonin receptor $2 \mathrm{~B} ; h \operatorname{tr} 2 c$, serotonin receptor $2 \mathrm{C}$; $t p h 1$, tryptophan hydroxylase 1; crh, corticotropin-releasing hormone; crhbp, crh-binding protein. (B) Canonical discriminant scores of each group. Groups centroids are marked by a small diamond, whereas circles indicate data distribution per group.

\subsubsection{Pituitary Gland}

Serotonin receptors $h t r 1 a \beta$ and $h$ tr $2 a$ were downregulated in the pituitary gland of all injected fish, at all time-points (Figure 7A,B, respectively). Expression level of $h t r 2 c$ was downregulated in FIA-injected fish sampled at $24 \mathrm{~h}$ compared to the $0 \mathrm{~h}$ group and was also lower in this group respect to CTRL regardless of sampling time (Supplementary File, Table S4).

The discriminant analysis to neuroendocrine variables had an overall satisfactory performance (Wilks $\lambda=0.43, p=0.028$ ), and the first two discriminant functions accounted for $88.4 \%$ of total data variability (Figure 8 ). The first function (F1, 58\%) was negatively loaded by $h t r 1 a \beta$ and $h t r 2 a$ (i.e., lower expression) (Figure $8 \mathrm{~A}$, correlations of -0.80 and -0.95 , respectively) whereas the second discriminant function (F2, 30.4\%) was positively loaded by gr1 (i.e., higher expression) (Figure 8A, correlation of 0.86 ). The analysis of Mahalanobis distances showed that group $0 \mathrm{~h}$ was significantly different from all FIA groups, FIA4 was different from FIA24, FIA48 and FIA72, and FIA24 also different from FIA48 ( $p \leq 0.05$, Figure 8B). 


\section{A}

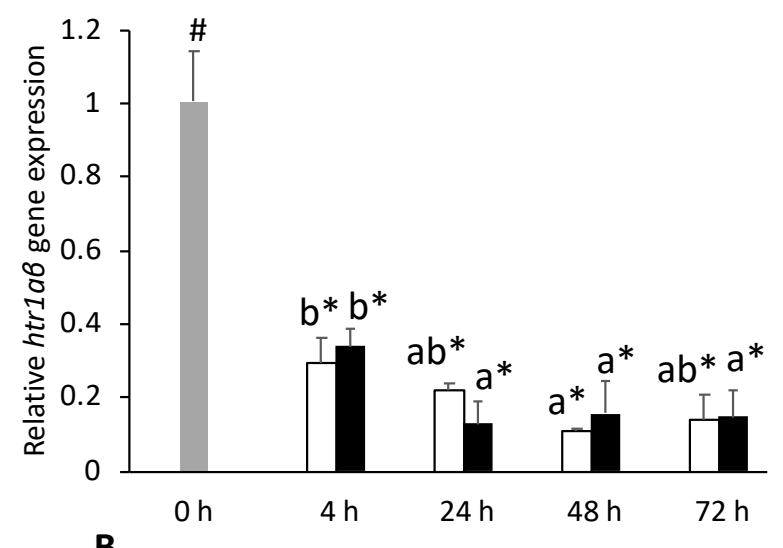

B

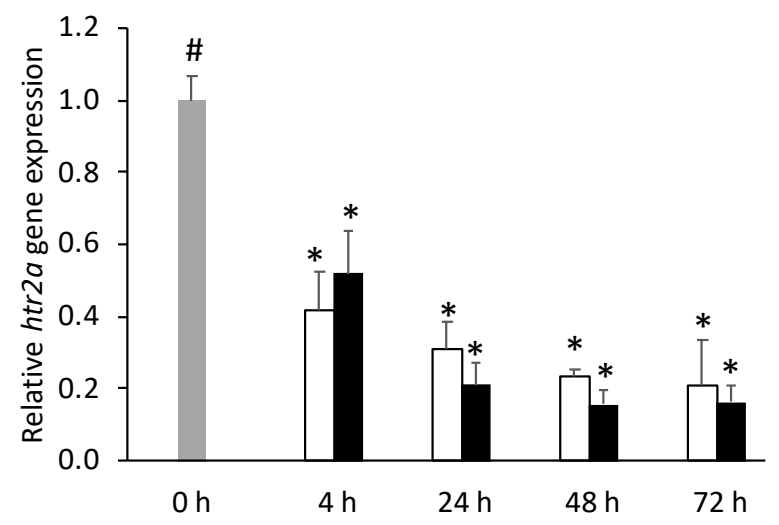

Figure 7. Pituitary gland expression of serotonin receptor $1 \mathrm{~A} \beta(h \operatorname{tr} 1 a \beta, \mathbf{A})$ and serotonin receptor $2 \mathrm{~A}$ $(h t r 2 a, B)$ in undisturbed European seabass $(0 \mathrm{~h}, \square)$ or i.p.-injected with a sham solution (CTRL, $\square)$ or

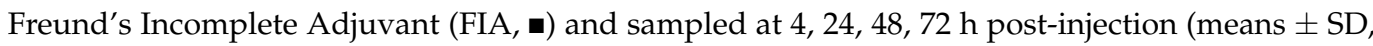
$\mathrm{n}=8$ ). Different symbols ( ${ }^{*}$ and \#) stand for significant differences between i.p.-injected groups and the undisturbed group $(0 \mathrm{~h})$. Capital letters stand for significant differences between stimuli. Lower-case letters indicate significant differences between sampling times. Further details in legend of Figure 1.

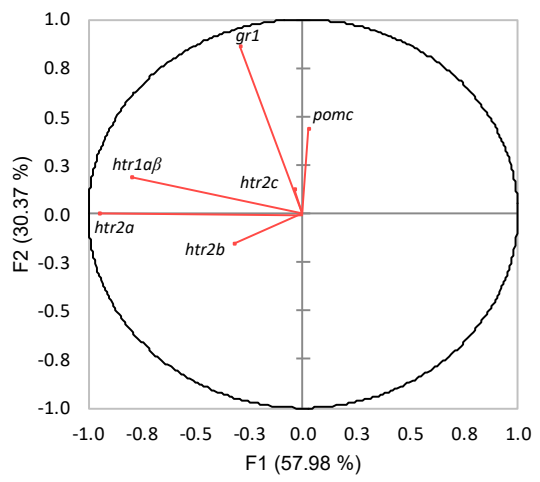

(A)

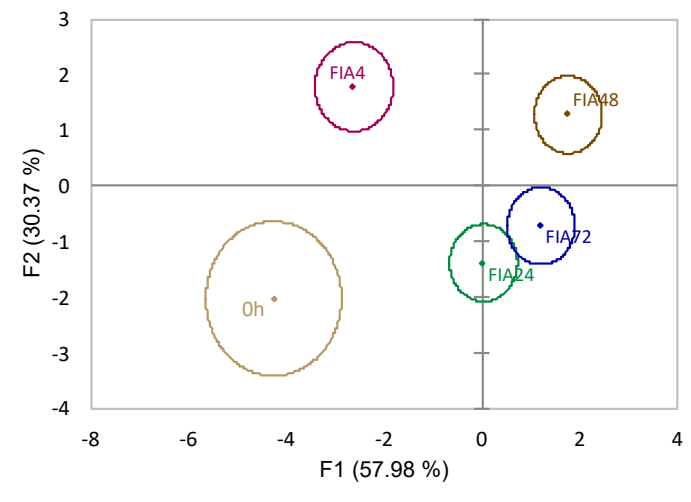

(B)

Figure 8. Canonical discriminant analysis of European seabass pituitary gland expression of HPI-axisrelated genes. (A) Correlation variables/factors (factor loads) for two main discriminant functions (F1 and F2); gr1, glucocorticoid receptor $1 ; h t r 1 a \beta$, serotonin receptor $1 \mathrm{~A} \beta ; h$ tr $2 a$, serotonin receptor $2 \mathrm{~A}$; $h$ tr $2 b$, serotonin receptor $2 \mathrm{~B}$; $h$ tr $2 c$, serotonin receptor $2 \mathrm{C}$; pomc, proopiomelanocortin. (B) Canonical discriminant scores of each group. Group centroids are marked by a small diamond, whereas circles indicate data distribution per group. 


\subsection{Opioid Receptors Response}

\subsubsection{Telencephalon}

Intra-peritoneal injection suppressed nociception receptor (nopr) gene expression in the telencephalon of CTRL and FIA groups from $24 \mathrm{~h}$ post-injection until the end of the experiment (Supplementary File, Table S1). The inflammatory condition enhanced opioid growth factor receptor 1 (ogfr 1 ) gene expression at $4 \mathrm{~h}$ respect to the CTRL group (Figure 9A), but expression levels significantly decreased at $4 \mathrm{~h}$ post-injection to values similar to those of the CTRL group. The mu opioid receptor (muor) expression was similarly upregulated in FIA-injected fish, in which expression was higher than that of the CTRL group at both 4 and $48 \mathrm{~h}$ post-injection (Figure 9B). At $4 \mathrm{~h}$, muor expression was also higher in FIA than $0 \mathrm{~h}$. Finally, the delta opioid receptor 2 (dor2) increased also significantly in fish under inflammation respect to CTRL fish, regardless of sampling time (Supplementary File, Table S1).

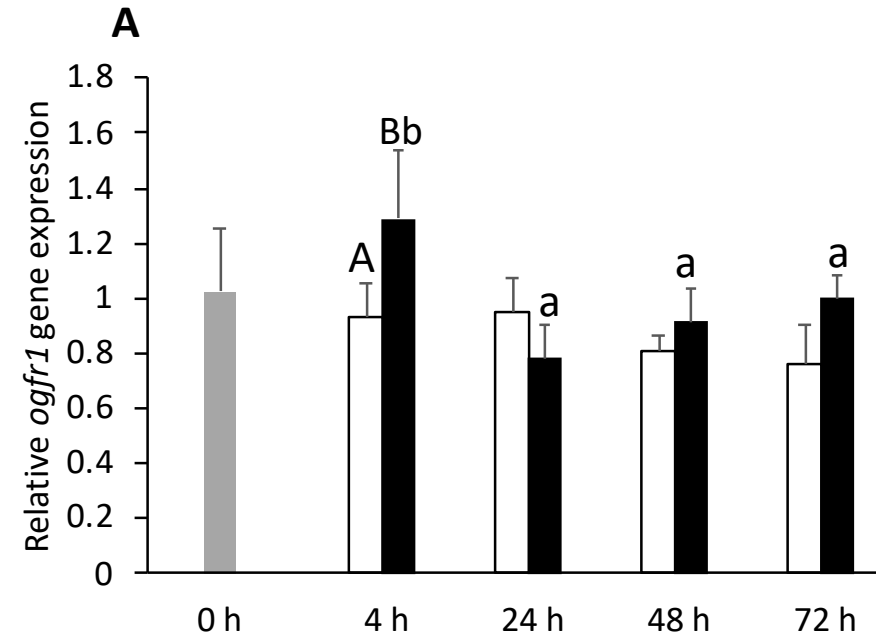

\section{B}

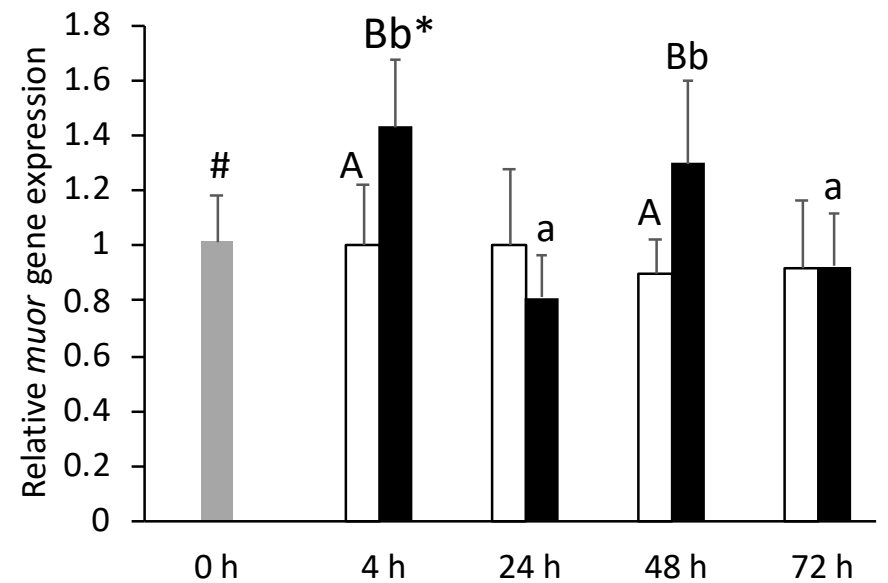

Figure 9. Telencephalic expression of opioid growth factor 1 (ogfr1, A) and mu opioid receptors $($ muor, $\mathbf{B})$ in undisturbed European seabass $(\mathrm{t} 0 \mathrm{~h}, \square)$ or i.p.-injected with a sham solution (CTRL, $\square$ ) or

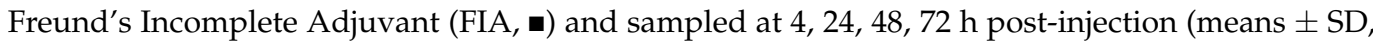
$\mathrm{n}=8$ ). Different symbols ( ${ }^{*}$ and \#) stand for significant differences between i.p.-injected groups and the undisturbed group $(0 \mathrm{~h})$. Capital letters stand for significant differences between stimuli. Lower-case letters indicate significant differences between sampling times. Further details in legend of Figure 1. 
The discriminant analysis for opioid receptors' gene expression of $0 \mathrm{~h}$ and FIA groups (Wilks $\lambda=0.2, p=0.004$ ) resulted in four linear functions from which the first two accounted for $89.8 \%$ of the data total variability (Figure 10). The first discriminant function (F1, $53.5 \%$ ) was negatively loaded by kappa opioid receptor 2 (kor2) and nociceptin opioid receptor (nopr) (i.e., lower gene expression) (Figure 10A, correlations of -0.61 and -0.93 , respectively) while the second function (F2, 36.4\%) was positively loaded by muor (i.e., higher gene expression) (Figure 10A, correlation of $0.85 \%$ ). The analysis of Mahalanobis distances between group's multivariate means showed that t0h was different from FIA24, FIA48, and FIA72. The FIA4 group was different from both FIA24 and FIA72. FIA24 was also different from FIA48 ( $p<0.05$, Figure 10B).

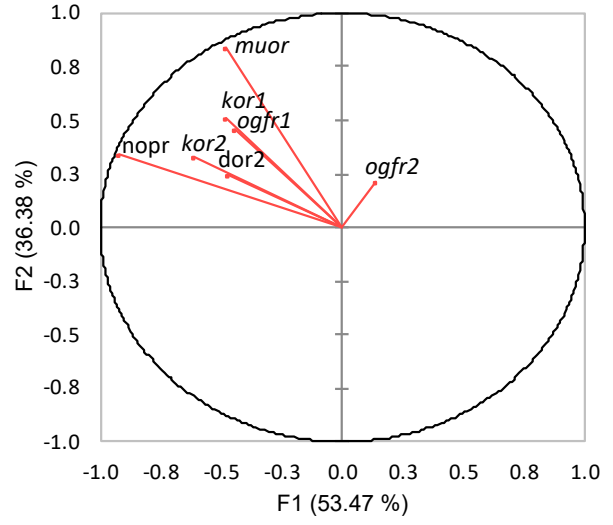

(A)

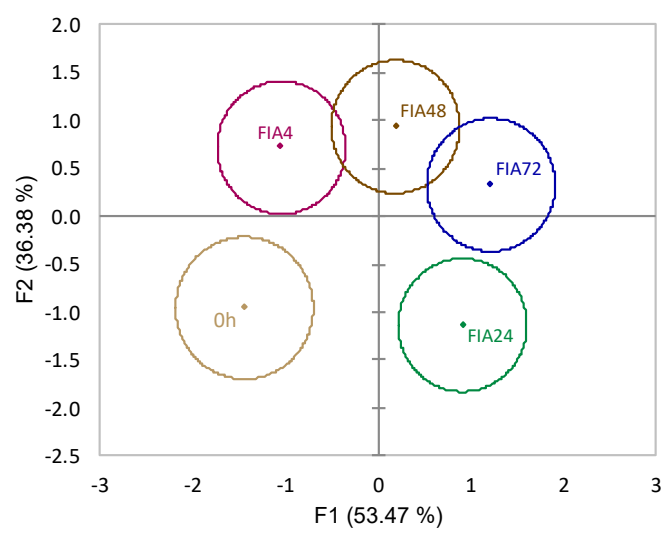

(B)

Figure 10. Canonical discriminant analysis of European seabass telencephalic expression of opioid receptor genes. (A) Correlation variables/factors (factor loads) for two main discriminant functions (F1 and F2); muor, mu opioid receptor; kor1, kappa opioid receptor 1; kor2, kappa opioid receptor 2; dor2, delta opioid receptor 2; ogfr1, opioid growth factor receptor 1, ogfr2, opioid growth factor receptor 2; nopr, nociceptin opioid receptor. (B) Canonical discriminant scores of each group. Group centroids are marked by a small diamond, whereas circles indicate data distribution per group.

\subsubsection{Optic Tectum}

In the optic tectum, inflammation seemed to carry out a transversal inhibitory effect where ogfr1 (at $4 \mathrm{~h}$ post-injection, Supplementary File, Table S2) and opioid growth factor receptor 2 (ogfr2) (at 24 and $48 \mathrm{~h}$ post-injection, Figure 11A) expression levels decreased in FIA-injected fish compared to CTRL fish. In addition, kor2, muor, and dor 2 were also downregulated in FIA fish, compared to CTRL fish, regardless of sampling point (Figure 11B). Moreover, nopr expression was lower in the FIA group than in CTRL group at both 4 and $24 \mathrm{~h}$ post-injection (Supplementary File, Table S2).

The performance of the discriminant analysis to opioid receptors gene expression showed no significant differences amongst data variability (Wilks $\lambda=0.4, p=0.13$ ). 
A
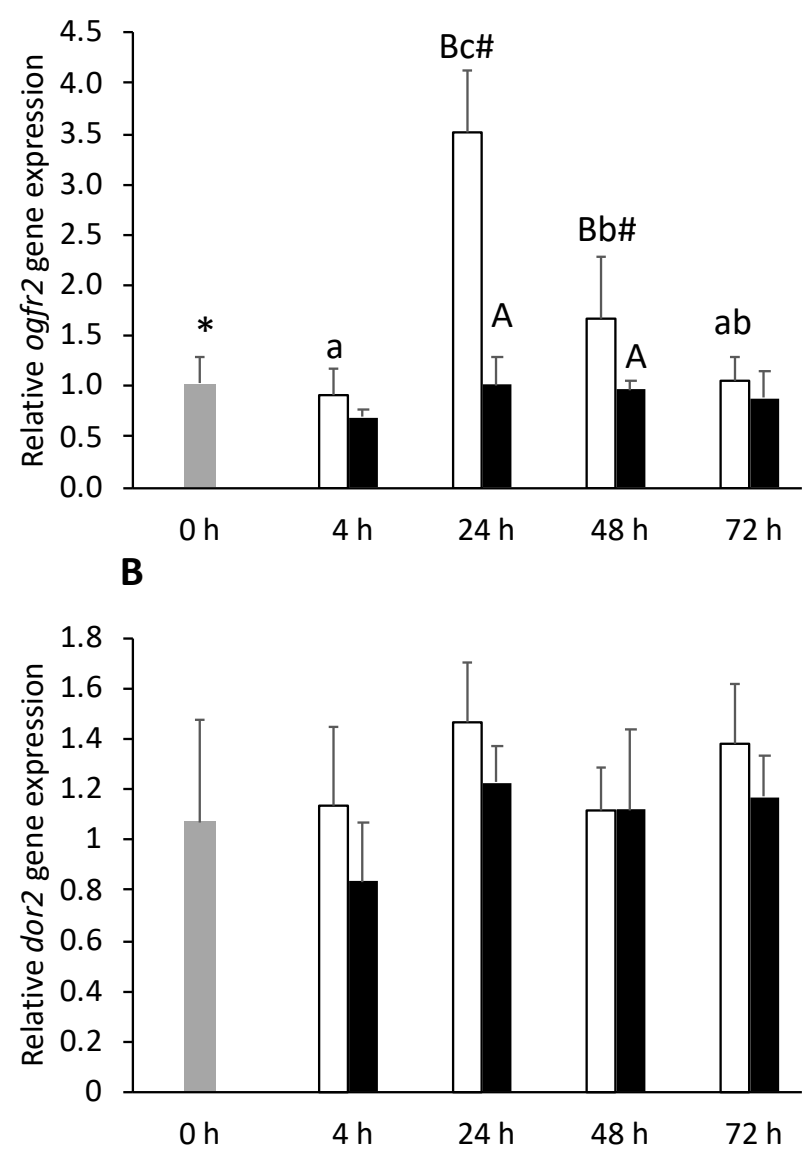

Figure 11. Optic tectum expression of opioid growth factor receptor $2(o g f r 2, \mathbf{A})$ and delta opioid receptor $2($ dor $2, \mathbf{B})$ in undisturbed European seabass $(0 \mathrm{~h}, \mathrm{\square})$ or i.p.-injected with a sham solution (CTRL, $\square$ ) or Freund's Incomplete Adjuvant (FIA, - ) and sampled at 4, 24, 48, $72 \mathrm{~h}$ post-injection (means $\pm S D, n=8$ ). Different symbols $\left({ }^{*}\right.$ and \#) stand for significant differences between i.p.-injected groups and the undisturbed group $(0 \mathrm{~h})$. Capital letters stand for significant differences between stimuli. Lower-case letters indicate significant differences between sampling times. Further details in legend of Figure 1.

\subsubsection{Hypothalamus}

Expression levels of both ogfr 1 and kor 2 were upregulated by inflammation whereas muor was downregulated. For the three affected transcripts, hypothalamic reaction to i.p. injection was earlier in the FIA group compared to CTRL group responses. Fish undergoing an inflammatory response increased expression levels of ogfr1, kor2 (Figure 12A), and dor2 (Figure 12B) in FIA fish at $48 \mathrm{~h}$ compared to their CTRL counterparts. Differently, it downregulated dor 2 transcription at $24 \mathrm{~h}$ respect to $0 \mathrm{~h}$ fish (Figure 12B). 

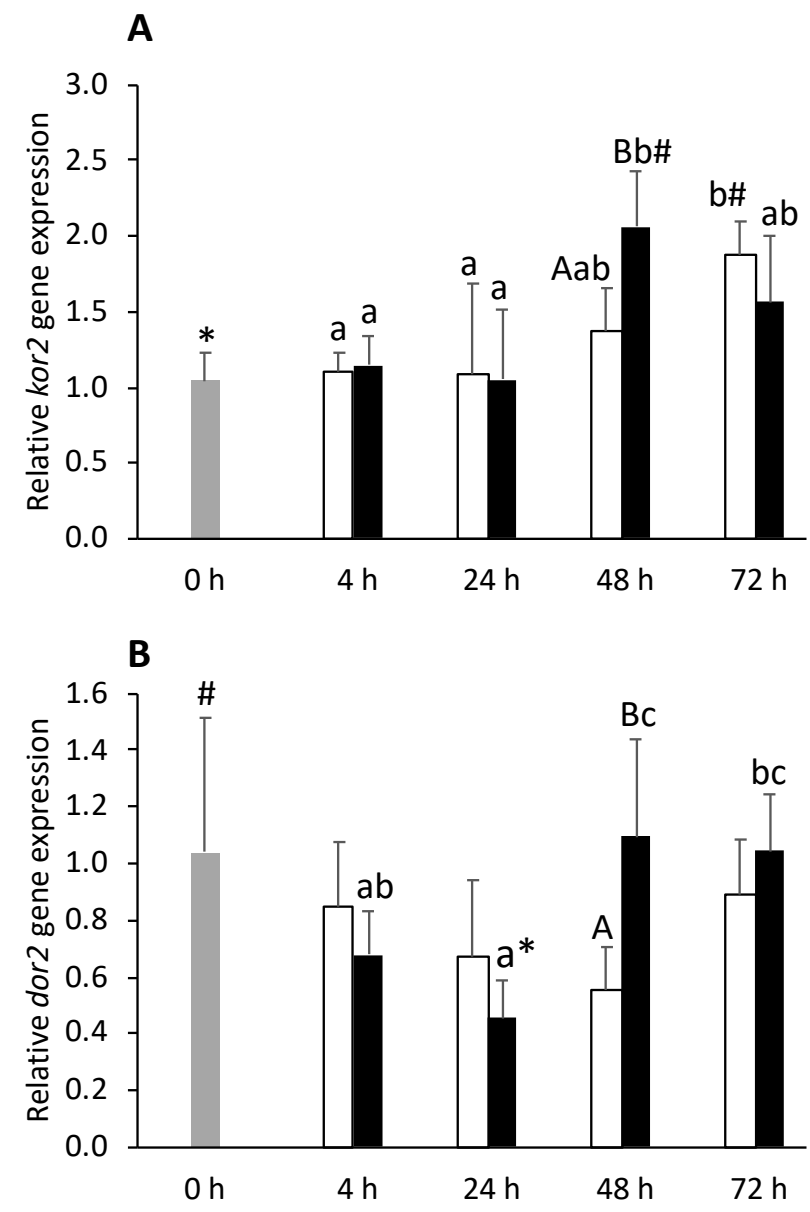

Figure 12. Hypothalamic expression of kappa opioid receptor 2 and delta opioid receptor 2 (kor2, A and dor $2, \mathbf{B})$ in undisturbed European seabass $(0 \mathrm{~h}, \square)$ or i.p.-injected with a sham solution (CTRL, $\square)$ or Freund's Incomplete Adjuvant (FIA, $\mathbf{m}$ ) and sampled at 4, 24, 48, $72 \mathrm{~h}$ post-injection (means \pm SD, $\mathrm{n}=8$ ). Different symbols ( ${ }^{*}$ and \#) stand for significant differences between i.p.-injected groups and the undisturbed group $(0 \mathrm{~h})$. Capital letters stand for significant differences between stimuli. Lower-case letters indicate significant differences between sampling times. Further details in legend of Figure 1.

The discriminant analysis (Wilks $\lambda=0.09, p<0.0001$ ) produced four discriminant functions from which the first two accounted for $83.5 \%$ of the total dataset variability (Figure 13). The first function (F1, 63.1\%) was positively loaded by ogfr2 (i.e., higher expression) (Figure 13A, correlation of 0.75) while the second function (F2, 20.4\%) was negatively loaded by kappa opioid receptor 1 (kor1), nopr, and dor 2 (i.e., lower gene expression) (Figure $13 \mathrm{~A}$, correlations of $-0.62,-0.76$, and -0.93 , respectively). The Mahalanobis distances between groups' multivariate means showed that $\mathrm{t} 0 \mathrm{~h}$ and FIA4 groups were significantly different from FIA24, FIA48, and FIA72, but not different from one another. Furthermore, FIA24 differed from FIA48 and FIA72, while FIA48 was also different from FIA72 $(p<0.05$, Figure 13B). 


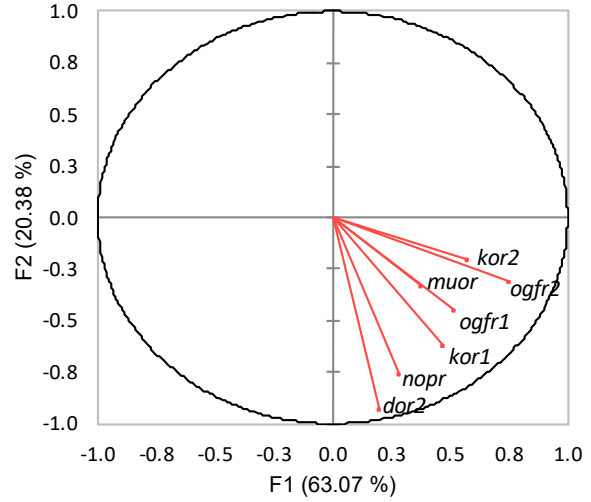

(A)

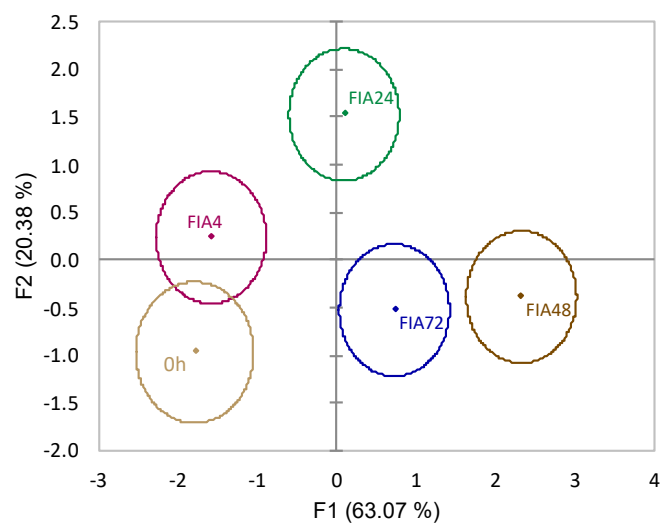

(B)

Figure 13. Canonical discriminant analysis of European seabass hypothalamic expression of opioid receptor genes. (A) Correlation variables/factors (factor loads) for two main discriminant functions (F1 and F2); muor, mu opioid receptor; kor1, kappa opioid receptor 1; kor2, kappa opioid receptor 2; dor2, delta opioid receptor 2; ogfr1, opioid growth factor receptor 1, ogfr2, opioid growth factor receptor 2; nopr, nociceptin opioid receptor. (B) Canonical discriminant scores of each group. Group centroids are marked by a small diamond, whereas circles indicate data distribution per group.

\subsubsection{Pituitary Gland}

In the pituitary gland, dor 2 gene expression was downregulated at $24 \mathrm{~h}$ in both injected groups (Figure 14). Otherwise, no effects of inflammation were detected in this tissue opioid receptors gene expression.

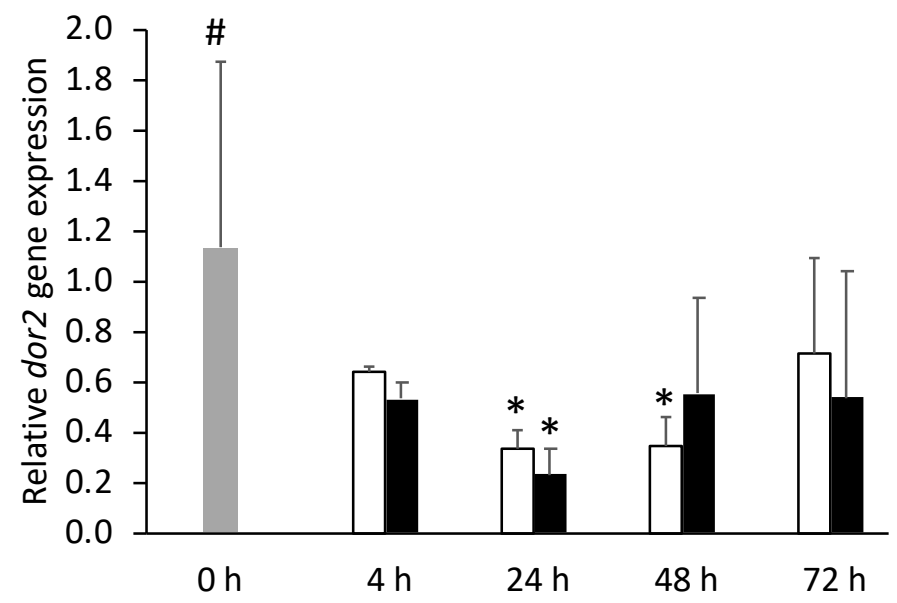

Figure 14. Pituitary gland expression of delta opioid 1 (dor 2$)$ in undisturbed European seabass $(0 \mathrm{~h}$, 口) or i.p.-injected with a sham solution (CTRL, $\square$ ) or Freund's Incomplete Adjuvant (FIA, $\mathbf{})$ and sampled at 4, 24, 48, $72 \mathrm{~h}$ post-injection (means $\pm S D, n=8$ ). Different symbols ( ${ }^{*}$ and \#) stand for significant differences between i.p.-injected groups and the undisturbed group $(0 \mathrm{~h})$. Further details in legend of Figure 1.

The first two linear functions resulting from data discriminant analysis (Wilks $\lambda=0.04$, $p<0.03$ ) explained $96.3 \%$ of the data variability (Figure 15). Both functions were negatively loaded by dor 2 (i.e., lower gene expression) (Figure 15A, correlations values of -0.61 and -0.75 , respectively). The analysis of Mahalanobis distances between groups' multivariate means showed that the FIA4 group was significantly different from and FIA24 and from FIA72 ( $p \leq 0.05$, Figure 15B). 


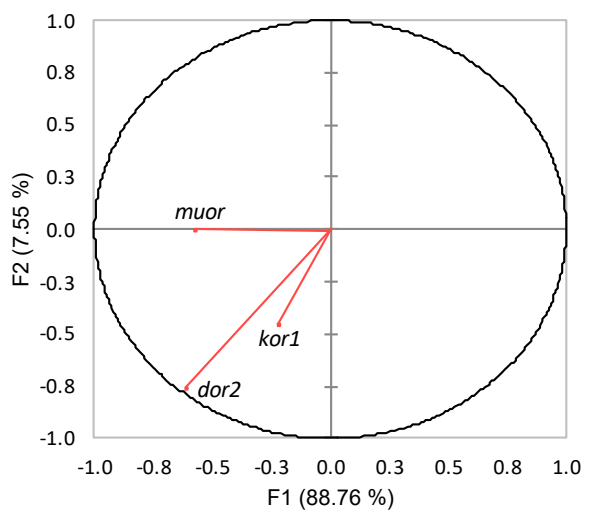

(A)

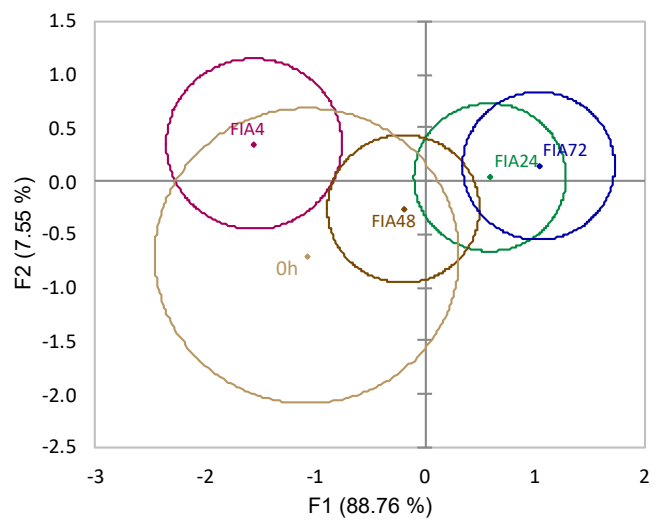

(B)

Figure 15. Canonical discriminant analysis of European seabass pituitary gland expression of opioid receptor genes. (A) Correlation variables/factors (factor loads) for two main discriminant functions (F1 and F2); muor, mu opioid receptor; kor1, kappa opioid receptor 1; dor2, delta opioid receptor 2. (B) Canonical discriminant scores of each group. Groups centroid are marked by a small diamond, whereas circles indicate data distribution per group.

\section{Discussion}

Fish handling is amongst the top stress-inducing procedures in aquaculture. Chasing and intra-peritoneally injecting fish, which involves air exposure, is a procedure often carried out during vaccination. It represents an acute stress that activates the HPI-axis and initiates a neuroendocrine response, irrespective of potential long-term physiological consequences [22,23]. In this study, while being aware of the acute stress (i.p. injection and/or air exposure) implications on brain gene expression, there was no intention to evaluate such effects. However, innate immune mechanisms are also triggered right after the immune challenge (FIA i.p. injection). Hence, our choice of sampling at such an early time point $(4 \mathrm{~h})$ implies that it is likely to witness some lingering stress effects (induced artifact due to injection procedure). Thus, they might mask those inflicted by the development of the inflammatory response at this early stage.

\subsection{HPI-Axis Response}

A stress-induced effect was observed in both experimental groups when crh, encoding for $\mathrm{CRH}$ - one of the first compounds to be released by the hypothalamic tissue upon neuroendocrine stimulation [7] - was found upregulated at $72 \mathrm{~h}$ post-injection. However, our sampling scheme most certainly missed a much earlier induction, previously demonstrated by Skrzynska and co-workers [22]. One would then expect rising plasma ACTH levels due to CRH-induced pituitary secretion of this hormone [7]. Despite the fact that we did not measure it directly, expression of pomc (ACTH genetic precursor) was evaluated in the pituitary gland but acute stress did not change its transcriptional rate. Transcription of pomc is regulated by several factors, including CRH (activation) and GR (impairment) [24]. GR1 was down-regulated in the pituitary gland at $72 \mathrm{~h}$, which would increase the expectations of observing pomc upregulation. Nonetheless, the absence of pomc transcriptional changes does not imply that there was no induction of ACTH response, since an expression enhancement could have occurred at an earlier time. Indeed, Liu and co-workers have observed the upregulation of $p o m c b$ in the pituitary gland of gilthead seabream, one hour following air exposure, with gene expression returning to basal levels at 6 and $24 \mathrm{~h}$ post stress [23]. Yet, transcription of pomca was not significantly altered by the acute stress, pointing at potentially different isoform functions. In the present study, the coding sequence selected for this gene does not specify to a particular isoform, but it shows high similarity degree to other teleost species' pomca nucleotide sequences. 
There are contrasting reports of stress and cortisol modulatory effects in which GR transcriptomic regulation is concerned [25-28]. In the head-kidney of European seabass leucocytes, both gr1 and gr2 were upregulated upon in vitro cortisol treatment [28]. The present study shows that these genes' behavior towards acute stress was the opposite. Specifically, gr1 was upregulated in the hypothalamus, whereas the telencephalic gr2 transcription was downregulated. There is a great gap in the knowledge of brain glucocorticoid receptors' distribution and dynamics in teleost fish, with most studies focusing on other tissues [28-30]. This central localization, where neuroendocrine pathways are initiated, indicates their involvement in mediating corticosteroid feedback mechanisms through transcriptomic regulation. The hypothalamic stress-responsive gr1 enhancement expression appears to be a regulatory mechanism triggered upon neuroendocrine stimulation. Accordingly, it was concomitant to $\mathrm{crh}$ higher expression levels in the same tissue.

In parallel to the stimulation at the central nervous system of the neuroendocrine response, acute stress also leads to a rise in monoaminergic activity. Nevertheless, these changes are known to occur almost immediately after the acute stress (chasing/handling/ injection), with levels typically returning to basal values within $4-8 \mathrm{~h}$ post-stress [31]. At $4 \mathrm{~h}$ post-injection, two of the evaluated serotonin receptors ( $h$ tr $1 a \beta$ and $h t r 2 a)$ were markedly downregulated in the pituitary gland. Moreover, in the hypothalamus, i.p. injection inhibited the gene expression of the serotonin synthesizing enzyme, tph1. Despite this being in opposition to what was observed by Gesto and co-workers [31], a similar inhibition

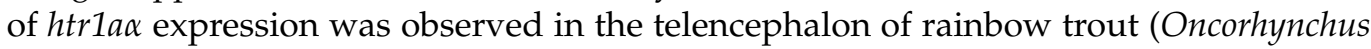
mykiss) $4 \mathrm{~h}$ after being subjected to acute stress (confinement, [32]). Gene expression data from this study do not allow to discriminate auto- from heteroreceptors. Nevertheless, and regardless of the extension and direction of this modulatory effect (which was not within the scope of this study), stress-induced downregulation of these receptors' gene expression, together with a decreased availability of serotonin synthesizing enzyme, suggests that the neuroendocrine response at some level regulates serotonergic activity. In support of this hypothesis, Medeiros and McDonald [33] showed in Gulf toad-fish that htr1a was downregulated by cortisol treatment, indicating that serotonin receptors were under negative feedback control of this hormone.

Intraperitoneal injection with a phlogistic agent elicits a local inflammatory response (FIA-injected fish). Overall some of these genes' behaviour was inverted while others were unaltered. What was remarkably clear was a regionalization of the brain response, i.e., establishing marked response patterns (stimulation vs. inhibition) according to different isolated regions. In what the telencephalon is concerned, i.p., injection with FIA induced the expression of three serotonin receptors, two of them ( $h t r 2 b$ and $h t r 2 c)$ at $4 \mathrm{~h}$ post-injection. Note that in mammals, this part of the brain includes the so-called limbic system consisting of structures that support several functions such as emotion, behaviour, and long-term memory. It is vastly innervated by serotonergic neurons coming from the raphe nuclei, and it interacts with the mammalian HPI-axis homolog, the hypothalamus-pituitary-adrenal axis [34]. In teleosts, an evident connection between telencephalic serotonin and HPI-axis has been demonstrated too [34-37]. Yet, little is known about the effect of peripheral immune signals on serotonergic pathways. The fact that there was an early induction of these serotonin receptors following the inflammatory insult might be related to circulating immune mediators such as cytokines, which are intensively produced at the onset of an immune response and have also been associated to the activation of mammalian central neuroendocrine pathways, including serotonergic pathways [10,38].

In line with the stimulatory pattern observed in the telencephalic region, the development of inflammatory response was accompanied by upregulation of both glucocorticoid receptors ( $g r 1$ and $g r 2$ ) and $h t r 1 a \alpha$ genes in the hypothalamus at $48 \mathrm{~h}$ post-injection. This was a response unexpectedly delayed in time considering these are mechanisms generally known to be mounted soon after the initial trigger [39], even when the trigger is an immune mediator (which begins to be synthesized at the onset of the inflammatory response [40]). Interestingly, this seemed to be a critical time point for the hypothalamic response, given 
several genes were differently expressed between control and FIA-injected fish at this time (including opioid-related genes). The ANOVA statistical approach did not retrieve significant alterations on the more obvious crh or crhbp genes. However, the discriminant analysis of data from the hypothalamus of fish undergoing inflammation attributed a significant role to these two genes which, together with both glucocorticoids ( $g r 1$ and $g r 2$ ) and one serotonin receptor (htr1aß), showed time-dependent increased expression. Altogether, it is important to be aware of the effects of an acute stress, such as a peritoneal injection and/or air exposure, particularly at this first stage of the HPI-axis physiology. The absence of a more rapid and stronger hypothalamic response might be explained by a masking effect of the intraperitoneal puncture.

In contrast to the observed in telencephalon and hypothalamus, the optic tectum reacted to immune signaling with a general inhibitory behaviour. Although this region is the primary visual center in the brain of the teleost [41], several studies (including nonmammalian) have demonstrated its involvement in other physiological mechanisms, such as the stress response [25,36,42]. In our experiment, both glucocorticoid receptors (gr1 and $g r 2$ ) and three serotonergic receptors ( $h t r 1 a \beta, h t r 2 a$, and $h t r 2 c)$ were less expressed in the optic tectum of fish undergoing an inflammatory response than control fish (injected with HBSS). Lower expression levels of these receptors suggest a general shutdown of glucocorticoid-mediated regulatory pathways as well as an impaired serotonergic activity. However, whether these are direct consequences of inflammatory signals and to what extent these changes affect other tectal functions is far from being understood. On matters of the teleostean brain function, information is scarce at best. However, these divergent responses amongst different brain regions indicate different functions of these tissues in order to face the same stimulus.

\subsection{Opioid Receptors}

Opioid neuropeptides are mainly synthesized at the central nervous system, but they are ubiquitously produced in the organism. Met-enkephalin, $\beta$-endorphin and dynorphin are produced from different gene precursors and bind to their specific receptors, except for met-enkephalin that may bind to delta opioid receptor, mu opioid receptor and the opioid growth factor receptor [43]. Similarly, opioid receptors are expressed in the teleost brain and other organs such as the head-kidney [17]. Recent findings further support their involvement in the immune response, demonstrating a direct effect of opioids on carp phagocyte immune function and immune-related gene expression $[18,44]$. On the other hand, opioid receptors expression has also been shown to be modulated by in vitro immune stimulation [17]. In mammals, opioids are mostly known to mediate nociception and mood and have long been studied regarding their clinical use as pain killers and their addiction properties [45]. However, there is quite a significant gap in fish regarding their central nervous system function since nociception is still a critically debated issue amongst fish biologists [15,46]. Even less effort has been put into understanding their main dynamics in response to peripheral immune stimuli.

As reviewed by Wei and Loh [47], muor transcriptional regulation was found to be mediated-among others-by endocrine factors, such as cytokines and interferon- $\gamma$, which demonstrates how sensitive these receptors are to immune stimulation in mammals. However, such knowledge has resulted from in vitro studies with immune-related cell lines, indicating that it is important to consider these receptors' localization when evaluating their transcriptional dynamics. In the brain, opioid receptors transcription is therefore likely to be differently regulated, even within different regions. In the present study, FIA-induced inflammation evoked a more noticeable hypothalamic ogfr1, kor2, and dor 2 gene expression enhancement than induced by the i.p. injection itself but only $48 \mathrm{~h}$ after the injection onset of inflammation. In addition, in the telencephalon, muor and ogfr 1 expressions were upregulated in FIA-injected fish, but this altered pattern was observed earlier at $4 \mathrm{~h}$ postinjection. Therefore, the two regions' reactivity to an immune challenge is differently characterized in receptor types and in the time it takes for their transcription rate to change, 
suggesting a differential role of telencephalon and hypothalamus after an inflammatory change. interestingly telencephalic serotonin receptors were, as aforementioned, similarly upregulated in parallel to the unfolding inflammatory process, suggesting that both receptor families (i.e., serotonin and opioids receptors) might be involved in the same neurologic response to immune signals. Indeed, Tao and Auberbach [48] have shown that opioid infusion into the rat brain induced a rise in extracellular serotonin, an effect blocked by a selective $\mu$-receptor antagonist, demonstrating the existence of a close relationship between both systems, at least in mammals. However, further studies are necessary in order to demonstrate a similar relationship in teleost.

Tectum opioid receptors behaved differently from the telencephalon and the hypothalamus and certainly to the pituitary gland, seemingly unaffected by inflammation. Indeed, and concerning what was observed with other neuroendocrine-related genes, most of the responding opioid receptor genes in the optic tectum were downregulated by inflammatory signaling, including those upregulated elsewhere. Far more than just the main visual center, the optic tectum is believed to gather other sensory modalities (electroreception, infra-red sensitivity, mechanoreception, etc.), then convey the acquired and processed information to motor neurons. Thereby, it is also involved in reactive behavior [49]. The responsiveness of opioid receptors in this particular region suggests that opioid peptides might also modulate sensory function. Additionally, in an inflammatory setting, these potential modulatory pathways seem to be altered, and so might be the resulting sensory and behavior functions.

\section{Conclusions}

Understanding how the fish brain processes peripheral inflammatory signals and whether such signaling molecules might trigger possible reactions is of great importance in fish health and welfare. The current approach yielded new data on the effect of a peritoneal inflammation on brain neuroendocrine response. Changes in various gene transcriptional rates in different brain regions-and in spite of the i.p. injection-induced stress-demonstrate the role of immune signals as transcriptional factors. It also shows their potential to regulate several brain-originated physiological responses such as the HPI-axis, behavior, nociception, and sensory functions. Finally, opioid receptors and other genes more directly involved with the neuroendocrine response are differently expressed in the evaluated brain regions, possibly pointing out the existence of site-specific functions.

Supplementary Materials: The following supporting information can be downloaded at: https: / / www.mdpi.com/article/10.3390/biology11030364/s1, Table S1. Telencephalic expression of neuroendocrine genes in the European seabass i.p. injected with Freud's Incomplete Adjuvant (FIA) or Hank's Balanced Salt Solution (CTRL) and sampled at 4, 24, 48 or $72 \mathrm{~h}$ post injection; Table S2. Optic tectum expression of neuroendocrine genes in the European seabass i.p. injected with Freud's Incomplete Adjuvant (FIA) or Hank's Balanced Salt Solution (CTRL) and sampled at 4, 24, 48 or $72 \mathrm{~h}$ post injection; Table S3. Hypothalamic expression of neuroendocrine genes in the European seabass i.p. injected with Freud's Incomplete Adjuvant (FIA) or Hank's Balanced Salt Solution (CTRL) and sampled at 4, 24, 48 or $72 \mathrm{~h}$ post injection; Table S4. Pituitary gland expression of neuroendocrine genes in the European seabass i.p. injected with Freud's Incomplete Adjuvant (FIA) or Hank's Balanced Salt Solution (CTRL) and sampled at 4, 24, 48 or $72 \mathrm{~h}$ post injection.

Author Contributions: Conceptualization, B.C. and J.M.M.; in vivo experiment, A.B. and B.C.; in silico search for the target genes coding sequences and primers design, R.A. and P.P.; RNA extraction and cDNA synthesis, M.M.; gene expression analysis and statistical analysis, R.A.; writing-original draft preparation, R.A.; writing-review and editing, R.A., P.P., M.M., A.B., J.M.M. and B.C. All authors have read and agreed to the published version of the manuscript. 
Funding: This work was supported by the project INFLAMMAA (PTDC/CVT-CVT/32349/2017), financed by Portugal and the European Union through FEDER, COMPETE 2020 and CRESC Algarve 2020, in the framework of Portugal 2020, and by national funds through Fundação para a Ciência e a Tecnologia (FCT, Portugal). National funds also supported this research through FCT within the scope of UIDB/04423/2020 and UIDP/04423/2020. FCT supported BC through 2020.00290.CEECIND. Patricia Pereiro wishes to thank the Axencia Galega de Innovación (GAIN, Xunta de Galicia) for her postdoctoral contract (IN606B-2018/010). This study was also partially supported by grant PID2020-117557RB-C22 (funded by MCIN/AEI/10.13039/501100011033 and by the European Union) to JMM.

Institutional Review Board Statement: The study was conducted according to the guidelines of the Declaration of Helsinki, and approved by the Institutional Review Board (or Ethics Committee) of the University of Cádiz (Spain) guidelines and the European Union Council (2010/63/EU) to use animals in research. The experimental procedures were previously approved by the Spanish Government's Ethics and Animal Welfare Committee (RD53/2013) and endorsed by the Regional Government (Junta de Andalucía reference number 28-04-15-241).

Informed Consent Statement: Not applicable.

Data Availability Statement: All data is provided in the main text or Supplementary File.

Conflicts of Interest: The authors declare no competing interest.

\section{References}

1. Ashley, P.J. Fish welfare: Current issues in aquaculture. Appl. Anim. Behav. Sci. 2007, 104, 199-235. [CrossRef]

2. Sneddon, L.; Wolfenden, D.; Thomson, J. Stress management and welfare. In Fish Physiology: Biology of Stress in Fish; Schreck, C.B., Tort, L., Farrell, A.P., Brauner, C.J., Eds.; Elsevier: Amsterdam, The Netherlands, 2016; Volume 35, pp. 463-539.

3. Sadoul, B.; Vijayan, M.M. Stress and Growth. In Fish Physiology: Biology of Stress in Fish; Schreck, C.B., Tort, L., Farrell, A.P., Brauner, C.J., Eds.; Elsevier: Amsterdam, The Netherlands, 2016; pp. 167-205.

4. Tort, L. Stress and immune modulation in fish. Dev. Comp. Immunol. 2011, 35, 1366-1375. [CrossRef]

5. Verburg-Van Kemenade, B.M.L.; Stolte, E.H.; Metz, J.R.; Chadzinska, M. Neuroendocrine-immune interactions in teleost fish. In Fish Neuroendocrinology, 1st ed.; Bernier, N.J., Kraak, G.V.D., Farrell, A.P., Colin, J.B., Eds.; Fish Physiology; Academic Press: Burlington, ON, Canada, 2009; Volume 28, pp. 313-364.

6. Costas, B.; Aragao, C.; Dias, J.; Afonso, A.; Conceicao, L.E.C. Interactive effects of a high-quality protein diet and high stocking density on the stress response and some innate immune parameters of Senegalese sole Solea senegalensis. Fish Physiol. Biochem. 2013, 39, 1141-1151. [CrossRef] [PubMed]

7. Gorissen, M.; Flik, G. The Endocrinology of the Stress Response in Fish. In Fish Physiology: Biology of Stress in Fish; Schreck, C.B., Tort, L., Farrell, A.P., Brauner, C.J., Eds.; Elsevier: Amsterdam, The Netherlands, 2016; pp. 75-111.

8. Azeredo, R.; Machado, M.; Martos-Sitcha, J.A.; Martinez-Rodriguez, G.; Moura, J.; Peres, H.; Oliva-Teles, A.; Afonso, A.; Mancera, J.M.; Costas, B. Dietary tryptophan induces opposite health-related responses in the Senegalese sole (Solea senegalensis) reared at low or high stocking densities with implications in disease resistance. Front. Physiol. 2019, 10, 508. [CrossRef] [PubMed]

9. Verburg-Van Kemenade, B.M.L.; Ribeiro, C.M.S.; Chadzinska, M. Neuroendocrine-immune interaction in fish: Differential regulation of phagocyte activity by neuroendocrine factors. Gen. Comp. Endocrinol. 2011, 172, 31-38. [CrossRef] [PubMed]

10. Engelsma, M.Y.; Huising, M.O.; van Muiswinkel, W.B.; Flik, G.; Kwang, J.; Savelkoul, H.F.J.; Verburg-van Kemenade, B.M.L. Neuroendocrine-immune interactions in fish: A role for interleukin-1. Vet. Immunol. Immunopathol. 2002, 87, 467-479. [CrossRef]

11. Hoglund, E.; Balm, P.H.M.; Winberg, S. Stimulatory and inhibitory effects of 5-HT1A receptors on adrenocorticotropic hormone and cortisol secretion in a teleost fish, the Arctic charr (Salvelinus alpinus). Neurosci. Lett. 2002, 324, 193-196. [CrossRef]

12. Winberg, S.; Nilsson, A.; Hylland, P.; Soderstom, V.; Nilsson, G.E. Serotonin as a regulator of hypothalamic-pituitary-interrenal activity in teleost fish. Neurosci. Lett. 1997, 230, 113-116. [CrossRef]

13. Khan, N.A.; Troutaud, D.; Moulinoux, J.P.; Deschaux, P. Characterization of serotonin receptors in fish brain: Polyamines inhibit the binding process. Neurosci. Res. Commun. 1996, 18, 97-105. [CrossRef]

14. Timothy, M.; Forlano, P.M. Serotonin distribution in the brain of the plainfin midshipman: Substrates for vocal-acoustic modulation and a reevaluation of the serotonergic system in teleost fishes. J. Comp. Neurol. 2020, 528, 3451-3478. [CrossRef]

15. Chervova, L.S.; Lapshin, D.N. Nociceptive thresholds in fish and its modulation by opioids. Eur. J. Neurosci. $2000,12,50$.

16. Eisenstein, T.K. The Role of Opioid Receptors in Immune System Function. Front. Immunol. 2019, 10, 2904. [CrossRef] [PubMed]

17. Chadzinska, M.; Hermsen, T.; Savelkou, H.F.J.; van Kemenade, B.M.L.V. Cloning of opioid receptors in common carp (Cyprinus carpio L.) and their involvement in regulation of stress and immune response. Brain Behav. Immun. 2009, 23, 257-266. [CrossRef] [PubMed]

18. Verburg-van Kemenade, B.M.L.; Savelkoul, H.F.J.; Chadzinska, M. Function of the Opioid System during Inflammation in Carp. Trends Comp. Endocrinol. Neurobiol. 2009, 1163, 528-532. [CrossRef] [PubMed] 
19. Tafalla, C.; Bogwald, J.; Dalmo, R.A. Adjuvants and immunostimulants in fish vaccines: Current knowledge and future perspectives. Fish Shellfish Immunol. 2013, 35, 1740-1750. [CrossRef] [PubMed]

20. Kuhl, H.; Beck, A.; Wozniak, G.; Canario, A.V.M.; Volckaert, F.A.M.; Reinhardt, R. The European sea bass Dicentrarchus labrax genome puzzle: Comparative BAC-mapping and low coverage shotgun sequencing. BMC Genom. 2010, 11, 68. [CrossRef]

21. Pfaffl, M.W. A new mathematical model for relative quantification in real-time RT-PCR. Nucleic Acids Res. 2001, 29, e45. [CrossRef]

22. Skrzynska, A.K.; Maiorano, E.; Bastaroli, M.; Naderi, F.; Miguez, J.M.; Martinez-Rodriguez, G.; Mancera, J.M.; Martos-Sitcha, J.A Impact of Air Exposure on Vasotocinergic and Isotocinergic Systems in Gilthead Sea Bream (Sparus aurata): New Insights on Fish Stress Response. Front. Physiol. 2018, 9, 96. [CrossRef]

23. Liu, X.H.; Khansari, A.R.; Teles, M.; Martinez-Rodriguez, G.; Zhang, Y.G.; Mancera, J.M.; Reyes-Lopez, F.E.; Tort, L. Brain and Pituitary Response to Vaccination in Gilthead Seabream (Sparus aurata L.). Front. Physiol. 2019, 10, 717. [CrossRef]

24. Drouin, J. 60 YEARS OF POMC Transcriptional and epigenetic regulation of POMC gene expression. J. Mol. Endocrinol. 2016, 56, T99-T112. [CrossRef]

25. Yao, M.; Hu, F.; Denver, R.J. Distribution and corticosteroid regulation of glucocorticoid receptor in the brain of Xenopus laevis. J. Comp. Neurol. 2008, 508, 967-982. [CrossRef] [PubMed]

26. Gądek-Michalska, A.; Spyrka, J.; Rachwalska, P.; Tadeusz, J.; Bugajski, J. Influence of chronic stress on brain corticosteroid receptors and HPA axis activity. Pharmacol. Rep. 2013, 65, 1163-1175. [CrossRef]

27. Terova, G.; Gornati, R.; Rimoldi, S.; Bernardini, G.; Saroglia, M. Quantification of a glucocorticoid receptor in sea bass (Dicentrarchus labrax, L.) reared at high stocking density. Gene 2005, 357, 144-151. [CrossRef] [PubMed]

28. Vazzana, M.; Vizzini, A.; Sanfratello, M.A.; Celi, M.; Salerno, G.; Parrinello, N. Differential expression of two glucocorticoid receptors in seabass (teleost fish) head kidney after exogeneous cortisol inoculation. Comp. Biochem. Physiol. A-Mol. Integr. Physiol. 2010, 157, 49-54. [CrossRef]

29. Vazzana, M.; Vizzini, A.; Salerno, G.; Di Bella, M.L.; Celi, M.; Parrinello, N. Expression of a glucocorticoid receptor (D1GR1) in several tissues of the teleost fish Dicentrarchus labrax. Tissue Cell 2008, 40, 89-94. [CrossRef]

30. Vizzini, A.; Vazzana, M.; Cammarata, M.; Parrinello, N. Peritoneal cavity phagocytes from the teleost sea bass express a glucocorticold receptor (cloned and sequenced) involved in genomic modulation of the in vitro chemiluminescence response to zymosan. Gen. Comp. Endocr. 2007, 150, 114-123. [CrossRef]

31. Gesto, M.; Lopez-Patino, M.A.; Hernandez, J.; Soengas, J.L.; Miguez, J.M. The response of brain serotonergic and dopaminergic systems to an acute stressor in rainbow trout: A time course study. J. Exp. Biol. 2013, 216, 4435-4442. [CrossRef]

32. Moltesen, M.; Laursen, D.C.; Thornqvist, P.O.; Andersson, M.A.; Winberg, S.; Hoglund, E. Effects of acute and chronic stress on telencephalic neurochemistry and gene expression in rainbow trout (Oncorhynchus mykiss). J. Exp. Biol. 2016, 219, 3907-3914. [CrossRef]

33. Medeiros, L.R.; McDonald, M.D. Cortisol-mediated downregulation of the serotonin 1A receptor subtype in the Gulf toadfish, Opsanus beta. Comp. Biochem. Physiol. A-Mol. Integr. Physiol. 2013, 164, 612-621. [CrossRef]

34. Lillesaar, C. The serotonergic system in fish. J. Chem. Neuroanat. 2011, 41, 294-308. [CrossRef]

35. Hoglund, E.; Balm, P.H.M.; Winberg, S. Skin darkening, a potential social signal in subordinate Arctic charr (Salvelinus alpinus): The regulatory role of brain monoamines and pro-opiomelanocortin-derived peptides. J. Exp. Biol. 2000, 203, 1711-1721. [CrossRef]

36. Overli, O.; Winberg, S.; Pottinger, T.G. Behavioral and neuroendocrine correlates of selection for stress responsiveness in rainbow trout-A review. Integr. Comp. Biol. 2005, 45, 463-474. [CrossRef]

37. Silva, P.I.M.; Martins, C.I.M.; Khan, U.W.; Gjoen, H.M.; Overli, O.; Hoglund, E. Stress and fear responses in the teleost pallium. Physiol. Behav. 2015, 141, 17-22. [CrossRef] [PubMed]

38. Hassanain, M.; Zalcman, S.; Bhatt, S.; Siegel, A. Interleukin-1 beta in the hypothalamus potentiates feline defensive rage: Role of serotonin-2 receptors. Neuroscience 2003, 120, 227-233. [CrossRef]

39. Arends, R.J.; Mancera, J.M.; Munoz, J.L.; Bonga, S.E.W.; Flik, G. The stress response of the gilthead sea bream (Sparus aurata L.) to air exposure and confinement. J. Endocrinol. 1999, 163, 149-157. [CrossRef] [PubMed]

40. Machado, M.; Azeredo, R.; Fontinha, F.; Fernandez-Boo, S.; Conceicao, L.E.C.; Dias, J.; Costas, B. Dietary methionine improves the European seabass (Dicentrarchus labrax) immune status, inflammatory response, and disease resistance. Front. Immunol. 2018, 9, 2672. [CrossRef]

41. Northmore, D.P.M. Holding visual attention for 400 million years: A model of tectum and torus longitudinalis in teleost fishes. Vis. Res. 2017, 131, 44-56. [CrossRef]

42. Lepage, O.; Vilchez, I.M.; Pottinger, T.G.; Winberg, S. Time-course of the effect of dietary L-tryptophan on plasma cortisol levels in rainbow trout Oncorhynchus mykiss. J. Exp. Biol. 2003, 206, 3589-3599. [CrossRef]

43. Przewlocki, R.; Przewlocka, B. Opioids in neuropathic pain. Curr. Pharm. Des. 2005, 11, 3013-3025. [CrossRef]

44. Chadzinska, M.; Savelkoul, H.F.J.; Verburg-van Kemenadea, B.M.L. Morphine affects the inflammatory response in carp by impairment of leukocyte migration. Dev. Comp. Immunol. 2009, 33, 88-96. [CrossRef]

45. Budd, K. Pain management: Is opioid immuno suppression a clinical problem? Biomed. Pharmacother. 2006, 60, 310-317. [CrossRef] [PubMed]

46. Sneddon, L.U. Evolution of nociception in vertebrates: Comparative analysis of lower vertebrates. Brain Res. Rev. 2004, 46, 123-130. [CrossRef] [PubMed] 
47. Wei, L.-N.; Loh, H.H. Transcriptional and epigenetic regulation of opioid receptor genes: Present and future. Annu. Rev. Pharmacol. 2011, 51, 75-97. [CrossRef] [PubMed]

48. Tao, R.; Auerbach, S.B. Opioid receptor subtypes differentially modulate serotonin efflux in the rat central nervous system. $J$. Pharmacol. Exp. Ther. 2002, 303, 549-556. [CrossRef] [PubMed]

49. Northmore, D.P.M. The Optic Tectum. In Encyclopedia of Fish Physiology: From Genome to Environment; Farrell, A.P., Ed.; Elsevier: Amsterdam, The Netherlands, 2011; Volume 1, pp. 131-142. 